${ }^{2}$ Department of Environmental Management, Jin-Wen Institute of Technology, Taipei, Taiwan, ROC

${ }^{3}$ South Regional Meteorological Center, Central Weather Bureau, Tainan, Taiwan, ROC

\title{
A diagnostic study on the environmental influence of a mesoscale convective system over southern China in Meiyu season
}

\author{
G. T.-J. Chen ${ }^{1}$, C.-C. Wang ${ }^{2}$, and C.-S. Hsieh ${ }^{3}$ \\ With 16 Figures \\ Received April 11, 2002; revised May 27, 2002; accepted July 14, 2002 \\ Published online: April 10, 2003 (C) Springer-Verlag 2003
}

\begin{abstract}
Summary
During the Post-TAMEX forecast experiment of Taiwan in 1992, a mesoscale convective system (MCS) developed on June 5-6 over southern China. As this system matured, it produced readily apparent cirrus outflow on satellite imageries while the upper level flow also exhibited a diffluent pattern. The purpose of the current study is to examine the possible changes in its environment associated with the development of this MCS.

By using 12-h data from 1200 UTC June 5 to 1200 UTC June 6 , objective analyses were performed for a $1^{\circ} \times 1^{\circ}$ latitude/longitude grid using sounding data and a low-pass filter. To facilitate the diagnosis, a band-pass filter was further applied to separate mesoscale features from macroscale ones, while the apparent heat source and apparent moisture sink defined by Yanai et al (1973) were also calculated.

Results suggest that the MCS exerted clearly discernable effects on its environment. The latent heat release led to the development of a warm core and mesoscale high-pressure disturbance at upper levels when the system matured. Ageostrophic winds and diffluent flow patterns together with strong anticyclonic vorticity at $200 \mathrm{hPa}$ near the MCS were associated with the mesohigh. After the mature stage, weak cooling occurred above $350 \mathrm{hPa}$, likely due to radiative emission from the cloud top. However, a mid-level cyclonic vortex, often present in MCSs over the North America, was not apparent here due to weak environmental vorticity and small Coriolis parameter $f$. The level of maximum divergence was initially located at $500 \mathrm{hPa}$, but rose to $200 \mathrm{hPa}$ as the MCS matured. In response, the upward motion not only intensi-
\end{abstract}

fied, but the level at which strongest rising occurred also ascended from 700 to $350 \mathrm{hPa}$. Results from the apparent heat source and moisture sink calculation suggest that this slow ascent of maximum heating was partially due to vertical transport of sensible heat by updrafts.

During the MCS's mature stage, under the stratiform clouds to the west of the strongest convection, a cold mesohigh formed at the surface due to evaporative cooling in downdrafts, and a gust front appeared along the leading edge of the outflow boundary. A trailing mesolow was also observed, likely due to near-adiabatic warming in drier downdrafts since no precipitation was associated with it.

\section{Introduction}

Since Maddox (1980a), observational studies of mesoscale convective systems (MCSs) have demonstrated the importance of warm air advection and moisture supply on their development. Induced by latent heat release associated with the deep convective clouds, a mid-level warm core structure and upper tropospheric mass outflow are often observed in mature MCSs. The primary influence of MCSs on their environment, therefore, has been suggested to be a mesoscale highpressure disturbance accompanied by strong anticyclonic outflow, as well as strong radiative cooling over the cloud top at upper levels 
(Maddox, 1980b; 1983; Maddox et al, 1981; Wetzel et al, 1983; Menard and Fritsch, 1989). These features have been reasonably well simulated by Maddox et al (1981) using the Drexel University/National Centers for Atmospheric Research (NCAR) mesoscale model, and by Zhang and Fritsch (1988) using the Pennsylvania State University (PSU)/NCAR mesoscale model (MM4).

A mesoscale mid-level cyclonic vortex (MCV) also often develops inside a MCS during its mature and dissipating stages, and is characterized by a warm core structure (Leary and Rappaport, 1987; Zhang and Fritsch, 1988; Menard and Fritsch, 1989; Bartels and Maddox, 1991; Johnson and Bartels, 1992; Fritsch et al, 1994; Trier et al, 2000). Zhang and Fritsch (1988) had successfully reproduced the warm vortex using MM4, and Zhang et al (1989) also suggested that mesovortices may develop over the region of stratiform clouds as squall lines reach their maximum intensity.

At lower levels near the surface, when MCSs mature strong mesoscale downdrafts below the stratiform precipitation can induce mesoscale high-pressure disturbance, followed by a wake low (Maddox et al, 1981; Wetzel et al, 1983; Johnson et al, 1989; Loehrer and Johnson, 1995). Such a mesoscale high, associated with subsidence and a cold pool, was analyzed using observational data by Zhang and Fritsch (1988) and reproduced in their MM4 simulations during the mature stage of the MCS. Regarding the wake low, Johnson et al (1989) has attributed its formation to near-adiabatic warming of the downbursts in a drier environment.

The above-mentioned studies on mesoscale features associated with MCSs were mostly for those in the North America during the warm season. Studies on MCSs over southern China and the adjacent area of Taiwan, on the other hand, have focused on their life span, large-scale environmental conditions, and characteristics of precipitation (e.g., Chen et al, 1986; Ma and Bosart, 1987; Chi and Chen, 1988; Lin, 1988; Laing and Fritsch, 1997; 2000). Researches on the effects of MCSs on their environment, to our knowledge, have been very few. Therefore, it is intriguing to investigate on the MCSs' influence on the atmospheric environment over the East Asia. The MCS case occurring over southern China during
5-6, June 1992, was chosen for such a study, and the main purpose is to examine the possible effects of this system on its environment.

\section{Case description}

During the period of Post-TAMEX forecast experiment (May-June) of Taiwan in 1992, a MCS developed on June 5-6 over southern China. This system moved eastward following the track shown in Fig. 1, and produced clear upper level cirrus outflow on satellite imageries when it matured between 1800 UTC June 5 and 0000 UTC June 6 (Fig. 2). The 200-hPa winds at 0000 UTC June 6 also exhibited a clear diffluent pattern at the location of the MCS (shaded area, Fig. 3b), but a similar phenomenon was absent both 12 hours before and after (Fig. 3a, c). This apparent connection between the change of upper-level large-scale flow pattern and the cirrus outflow from the MCS near 0000 UTC June 6 has motivated us to undertake the present study.

Figure $4 \mathrm{a}$ presents detailed surface pressure analysis at 0000 UTC June 6 , which reveals that there existed a mesohigh below the region of stratiform precipitation near $28^{\circ} \mathrm{N}, 110^{\circ} \mathrm{E}$, west of the convection (shaded) when the MCS matured (c.f., Fig. 2c). The central pressure of the mesohigh was about $1006 \mathrm{hPa}$, with anticyclonic flow especially visible to the east. Along the leading edge of the surface outflow there existed a gust front, with top wind speed in excess of $20 \mathrm{kts}$ (Fig. 4a). To the west of the mesohigh, there was also a mesoscale wake

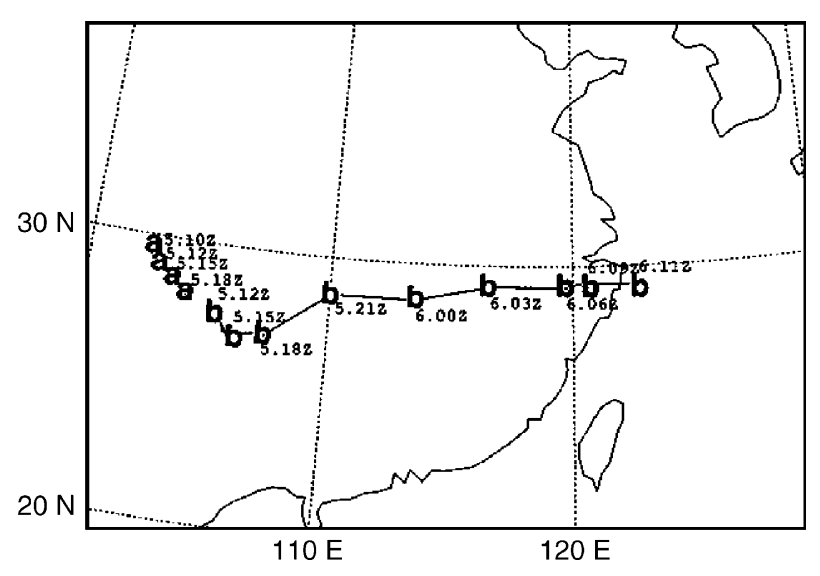

Fig. 1. Track of the MCS (denoted as "b") discussed in this paper from 1200 UTC June 5 to 1100 UTC June 6, 1992. Track of another MCS (denoted as "a") is also shown 

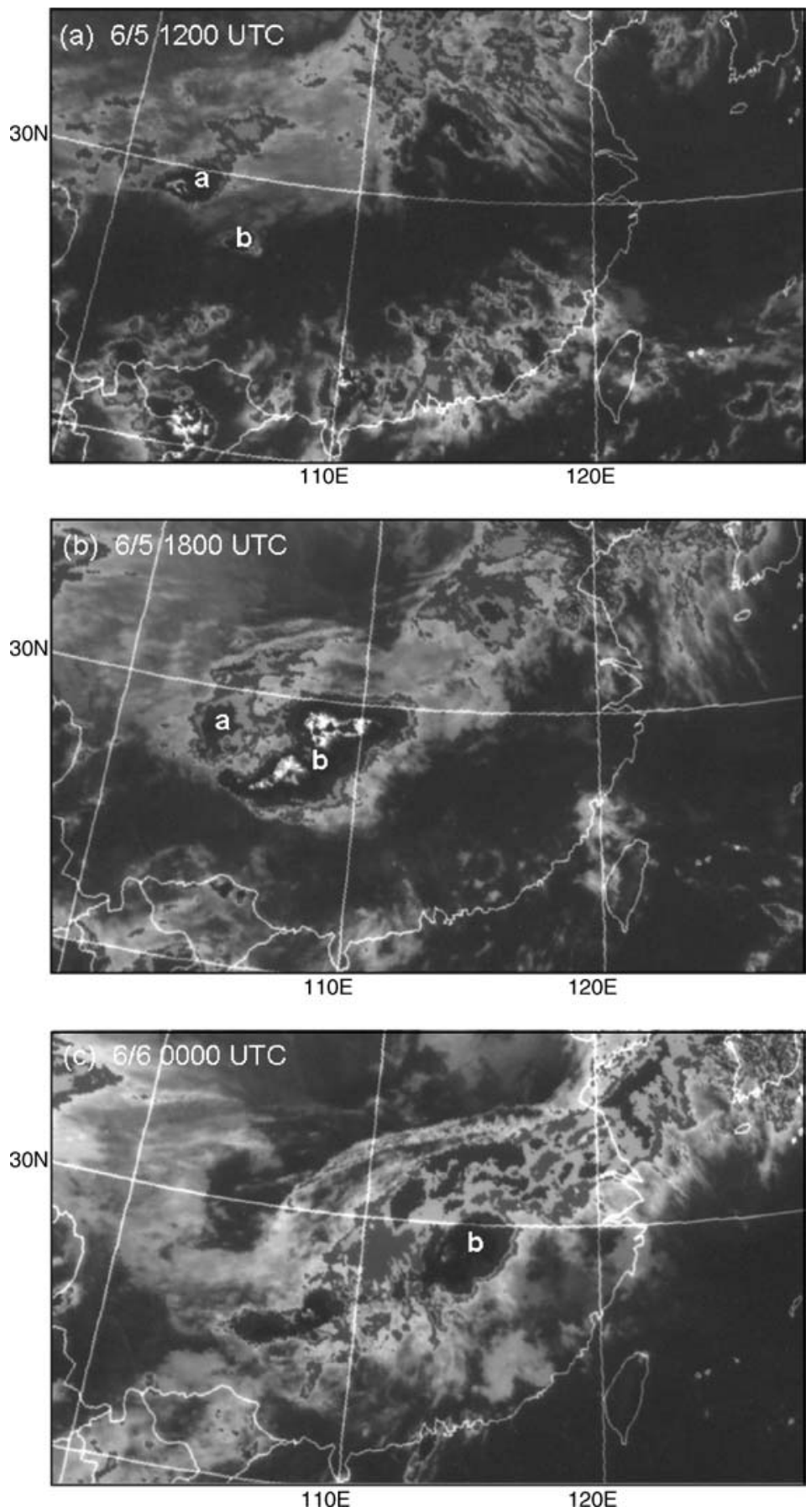

Fig. 2. Color-enhanced infrared GMS satellite imageries for a 1200 UTC, b 1800 UTC June 5, c 0000 UTC, d 0600 UTC, and e 1100 UTC June 6. Imageries are 6 hours apart except for $\mathbf{e}$ low, with cyclonic flow pattern and a central pressure of about $1004 \mathrm{hPa}$. Surface temperature analysis (Fig. 4b) indicates that the cold pool nearly collocated with the mesohigh, at regions where strong flow behind the gust front originated. The wake low, in contrast, was warmer than its surroundings. Although the wake low was also below the stratiform-cloud shield (Fig. 2c), significant precipitation did not occur in the adjacent area according to weather reports of the station model plots (omitted in Fig. 4). This suggests that the downdrafts were drier and contained less liquid water available for evaporation, and hence the wake low might form through adiabatic warming of subsidence. Therefore, many features typically found in MCSs in the North America were also observed in the present case (e.g., Fujita, 1959; Zipser, 1977; Loehrer and Johnson, 1995), which occurred over southern China. 

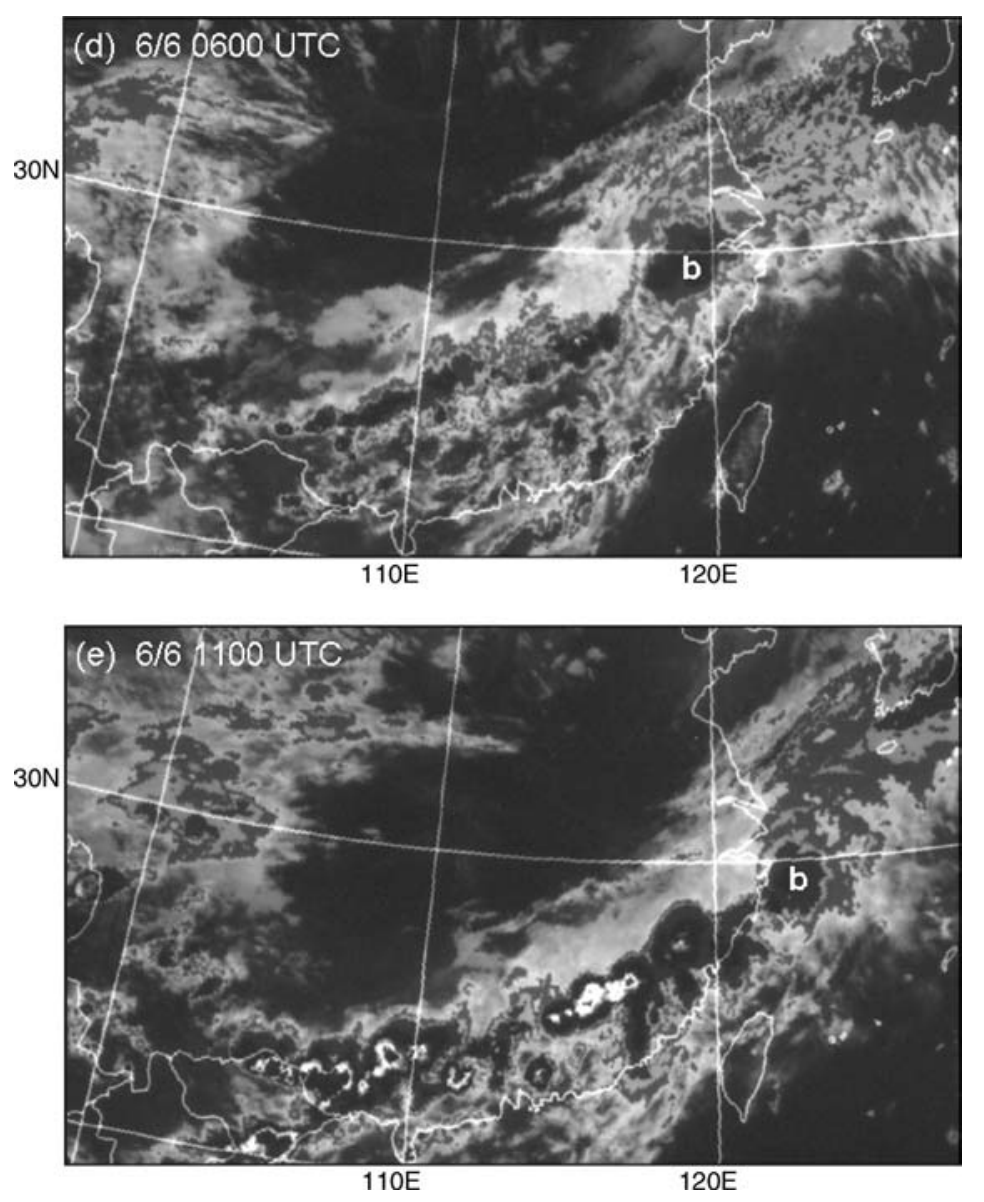

Fig. 2 (continued)

\section{Data and methodology}

Data used in this study included surface observations over East Asia for 0000 UTC June 6, as well as 12-h upper air sounding and weather maps at eight pressure levels $(925,850,700$, $500,400,300,200$, and $100 \mathrm{hPa}$ ) from 1200 UTC June 5 to 1200 UTC June 6, 1992. Colorenhanced infrared imageries from GMS satellite at 3-h intervals were also used. From unevenly spaced sounding data, objective analyses of various meteorological fields (including geopotential height, $u$ - and $v$ - components of wind, temperature, and dew-point) were first obtained using the low-pass filtering technique developed by Barnes $(1964 ; 1973)$. The analysis domain was a rectangular area of $103^{\circ}-125^{\circ} \mathrm{E}, 23^{\circ}-$ $35^{\circ} \mathrm{N}$, with a grid resolution of $1^{\circ} \times 1^{\circ}$ latitude/longitude. Parameters related to moisture, such as relative humidity and horizontal moisture flux, were subsequently calculated from the objective analyses.

To isolate mesoscale features, a band-pass filter (Doswell, 1977) was further applied to two- dimensional (2-D) meteorological fields of geopotential height, temperature, and wind to achieve scale separation of mesoscale and macroscale. Kinematic parameters (including relative vorticity, divergence, and vertical velocity) were calculated separately for mesoscale and macroscale features. Subjective analyses were also performed and used as an independent data source to compare with the result obtained from scale separation. The apparent heat source $\left(Q_{1}\right)$ and apparent moisture sink $\left(Q_{2}\right)$ as defined by Yanai et al (1973) were also computed using the objective analyses to facilitate the diagnosis of the MCS and the discussion of possible effects on its environment. Detailed methods employed for objective analysis, scale separation, and calculation of $Q_{1}$ and $Q_{2}$ are described below.

\subsection{Space filtering and scale separation}

Barnes $(1964 ; 1973)$ developed an objective analysis technique that filters out high-frequency short waves from 2-D meteorological fields by 

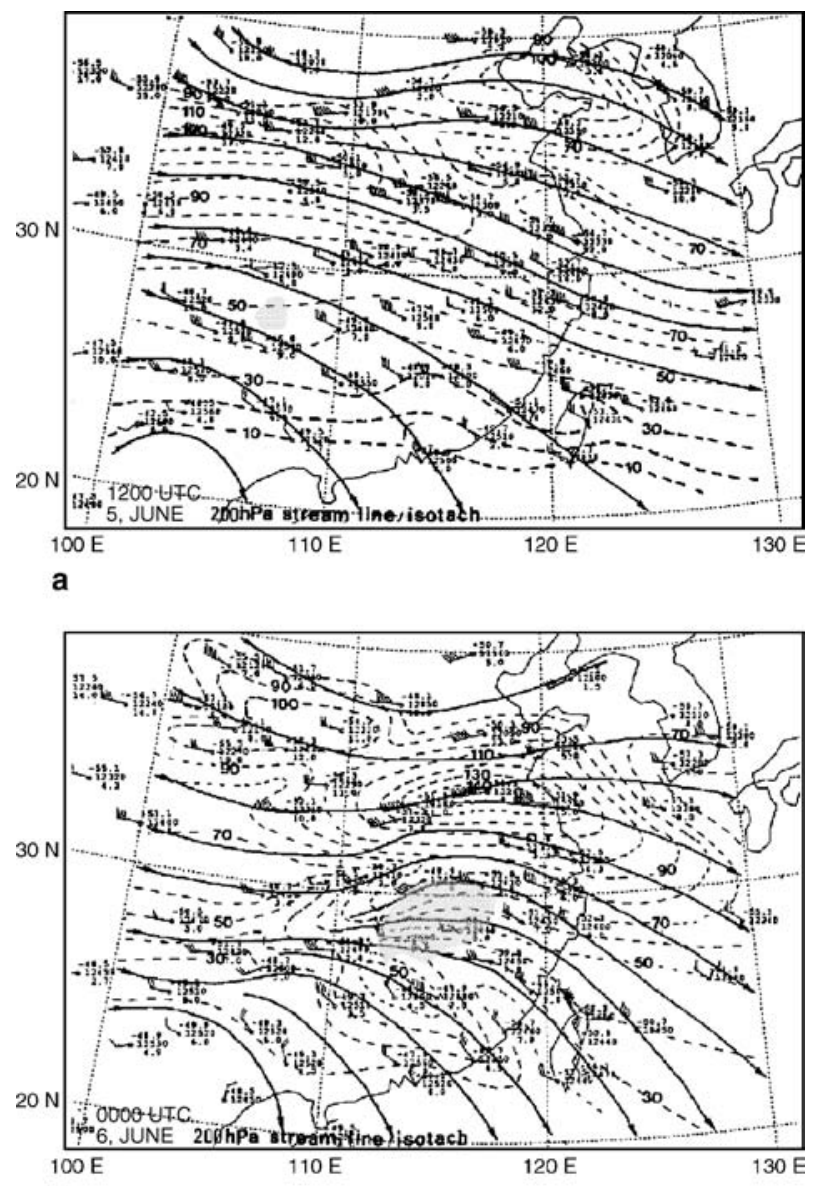

b

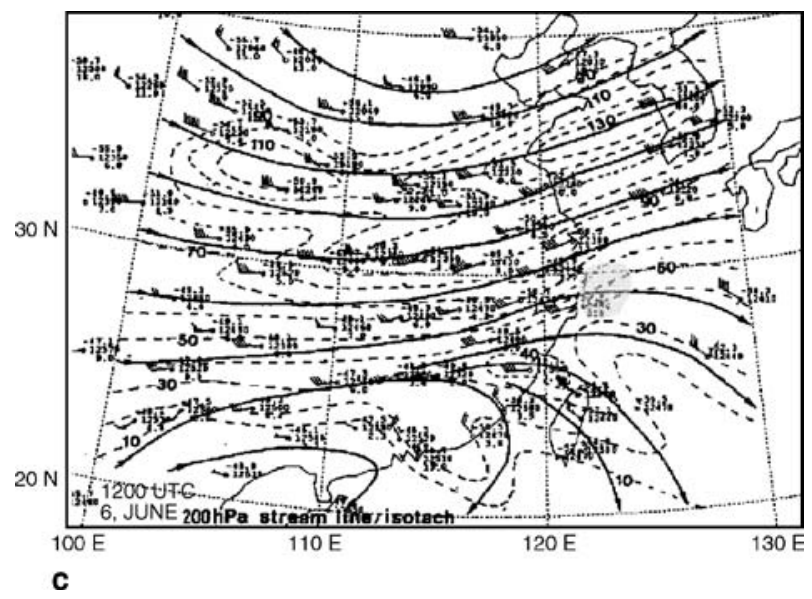

Fig. 3. 200-hPa streamlines (solid arrow lines) and isotachs (kts; dashed lines) at a 1200 UTC June 5, b 0000 UTC June 6, and c 1200 UTC June 6. Contour intervals for isotachs are $10 \mathrm{kts}$, and shadings indicate regions of the MCS with cloud-top temperature below $-52^{\circ} \mathrm{C}$

appropriate specification of response (weighting function) to the wavelength spectrum. Such a low-pass filter was used as the first step to obtain smoothed and objectively analyzed fields from

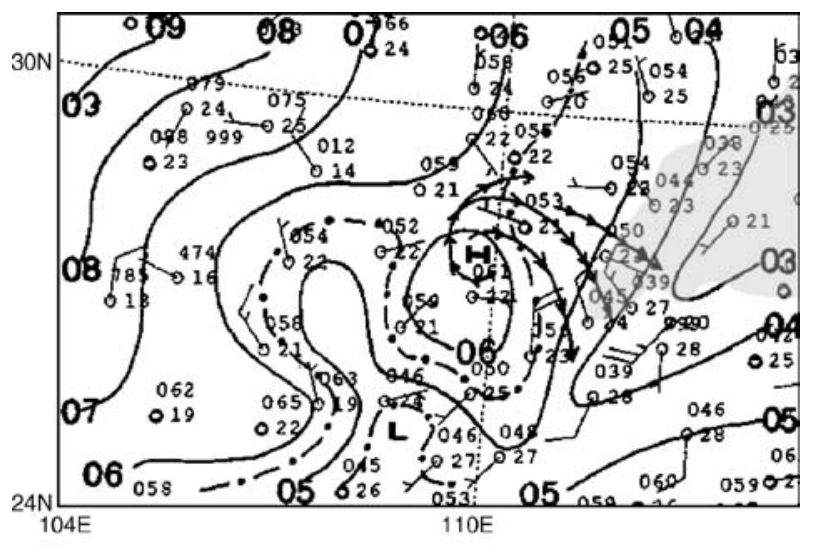

a

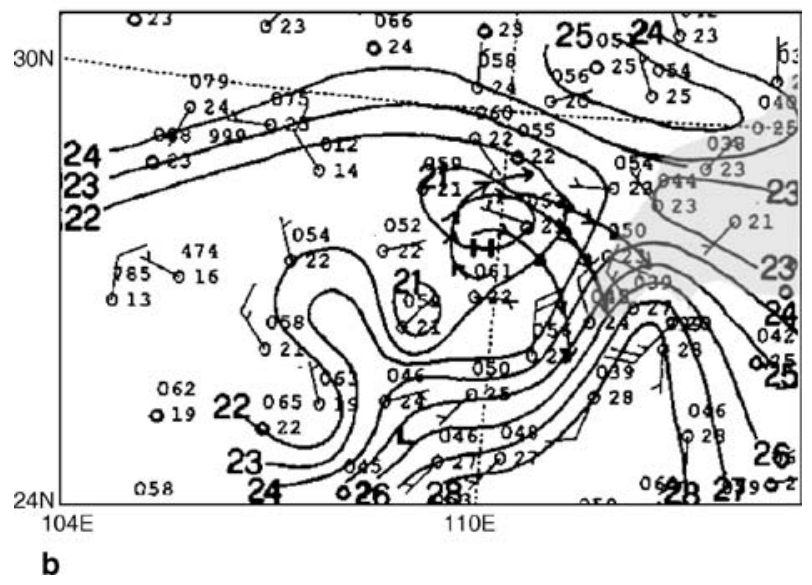

Fig. 4. Surface mesoscale analyses for a pressure, and b temperature over southern China at 0000 UTC June 6, 1992. Intervals for isobars are $1 \mathrm{hPa}$ (with first two digits omitted) and $0.5 \mathrm{hPa}$ (dot-dashed lines) as appropriate, and for isotherms are $1{ }^{\circ} \mathrm{C}$. Letters " $\mathrm{H}$ " and " $\mathrm{L}$ " mark centers of mesohigh and mesolow, while arrow lines indicate streamlines of airflow from the mesohigh. Shadings indicate regions of the MCS with cloud-top temperature below $-52{ }^{\circ} \mathrm{C}$

sounding data. For each grid point, the method assigns weights of data from surrounding stations (within a specified radius of influence) according to the distance and a weighting parameter $C$. When applying the method, the user specifies an ideal wavelength $\lambda$, a final response function $R$, and another weighting function parameter $G$ $(0<G<1)$, and the scheme computes $C$ and obtains a convergent value as the final low-pass estimate at each grid point through iteration. The purpose of function $G$ is to increase the speed for reaching a convergent analysis (Barnes 1973), while during the iteration the intermediate estimates at stations were interpolated using values at the closest four grid points (Lin and Chiou, 1985). 
Doswell (1977) adopted the filter of Barnes (1964) and designed a procedure of band-pass analysis whose response curve is defined as the difference between two low-pass fields. As a result, the band-pass filter has peak response at a particular mesoscale wavelength, and it served as the second step to achieve the actual scale separation. Assume that $R 1$ and $R 2$ are two low-pass response curves using weighting function parameters of $C 1$ and $G 1$, and $C 2$ and $G 2$, respectively, then the band-pass response function $B R$ (Maddox, 1980b) is given by

$B R=\gamma(R 1-R 2)$,

where $\gamma=1 /(R 1-R 2)$ and the full (100\%) response is restored at a particular mesoscale wavelength of interest $\left(\lambda_{\max }\right)$. Therefore, in designing a band-pass filter, $\lambda_{\max }$ must be first determined. Doswell (1977) suggests that $\lambda_{\max }$ should be at least twice the resolution of observing network. With an averaged station distance of about $240 \mathrm{~km}$ over southern China and considering the size of the MCS in mature stage (Fig. 2c), a $\lambda_{\max }$ of $500 \mathrm{~km}$ was chosen. Then, different response curves were constructed by using $G$ values at 0.1 intervals, and eventually two of them (with $G 1$ and $G 2$ ) were subjectively selected as $R 1$ and $R 2$, with constraining conditions that $R 1-R 2>0.4$ over the wavelength range of interest and $R 1-R 2=0.8$ at $\lambda_{\max }$. Then, parameters $C 1$ and $C 2$ are obtained, while $\gamma$ is set to 1.25 in order for $B R$ to achieve $100 \%$ at $\lambda_{\max }$. Thus, $B R$ has values between 0.5 and 1.0 over the range of mesoscale wavelength to our interest.

The response functions that we used are shown in Fig. 5, in which $R 2$ is the low-pass response curve used to obtain our objective analyses, $B R$ is the mesoscale band-pass response curve used to retrieve mesoscale features, and $T R=B R+\gamma R 2$ depicts the total response curve. The parameter settings were $G 1=0.3, G 2=0.4, C 1=5000$, $C 2=40000$, and $\lambda_{\max }=500 \mathrm{~km}$ as mentioned. The resulted total fields preserved motions with wavelength greater than $300 \mathrm{~km}$, while wavelengths of $300-1000 \mathrm{~km}$ were considered mesoscale and those longer than $1000 \mathrm{~km}$ were considered macroscale. Using methods described above, mesoscale and macroscale features in the objective analyses were separated, and conversely the total field can be recovered by adding the two components together.

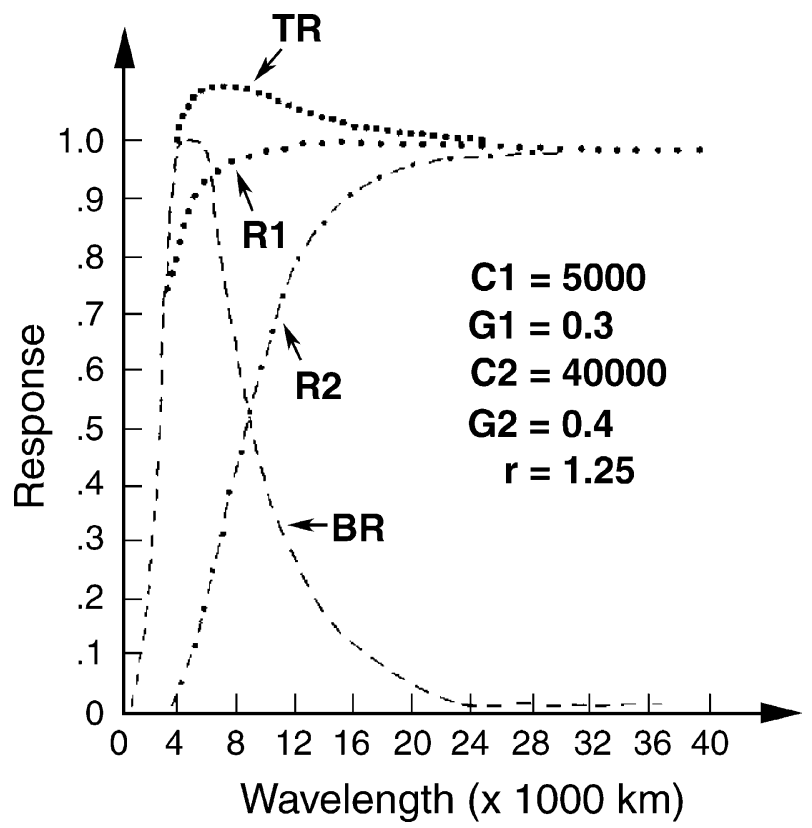

Fig. 5. Low-pass and band-pass response curves used in the present study as functions of wavelength. $R 1$ and $R 2$ are the mesoscale and macroscale low-pass response curves, $B R=\gamma(R 1-R 2)$ is the mesoscale band-pass response curve, and $T R=B R+\gamma R 2$ depicts the total response curve. Values used for $\gamma$ and weighting parameters $G 1, G 2$, $C 1$, and $C 2$ are $1.25,0.3,0.4,5000$, and 40000 , respectively, and the combination yields a maximum response of $B R$ at a wavelength of $500 \mathrm{~km}$ (see text for further explanation)

\subsection{Apparent heat source and apparent moisture sink}

Yanai et al (1973) defined the apparent heat source $\left(Q_{1}\right)$ and apparent moisture sink $\left(Q_{2}\right)$ as

$$
\begin{aligned}
Q_{1} & =\frac{\partial \bar{S}}{\partial t}+\overline{\nabla \cdot S \boldsymbol{V}}+\frac{\partial}{\partial p} \overline{\omega S} \\
& =Q_{R}+L(\overline{\boldsymbol{C}}-\bar{E})-\frac{\partial}{\partial p} \overline{\omega^{\prime} S^{\prime}}, \\
Q_{2} & =-L\left(\frac{\partial \bar{q}}{\partial t}+\overline{\nabla \cdot q \boldsymbol{V}}+\frac{\partial}{\partial p} \overline{\omega q}\right) \\
& =L(\bar{C}-\bar{E})+L \frac{\partial}{\partial p} \overline{\omega^{\prime} q^{\prime}},
\end{aligned}
$$

where $S=C_{p} T+g z$ is the dry static energy, $Q_{R}$ is net radiative heating/cooling rate, $L$ is latent heat of condensation/vaporization, $C$ and $E$ are condensation and evaporation rates, $q$ is mixing ratio, while other symbols have their usual meteorological meaning. The over bar $\left(^{-}\right)$ denotes the areal-mean inside a specified region, and prime $\left({ }^{\prime}\right)$ denotes the deviation from that 
mean. Thus, the apparent heat source $\left(Q_{1}\right)$, or the mean local tendency of dry static energy plus the mean divergence of its three-dimensional (3-D) fluxes of a fixed region, comes from radiation, latent heating from net condensation, and vertical convergence of vertical eddy flux of sensible heat. The apparent moisture sink $\left(Q_{2}\right)$, similarly, is due to net condensation and vertical divergence of vertical eddy flux of moisture.

The calculation by Cox and Griffith (1979) for the tropical low in North Atlantic was adopted as the vertical distribution of $Q_{R}$. For $Q_{1}$ and $Q_{2}$ in Eqs. (2) and (3), 12-h changes were used for local tendency terms (time-integrated form), while averages of successive synoptic times were used for flux convergence/divergence. Kinematic method was used to compute vertical velocity $(\omega)$, and adjustment was made following O'Brien (1970) by assuming $\omega$ vanishes at $100 \mathrm{hPa}$. At the lower boundary, taken to be $925 \mathrm{hPa}$ here, vertical motion induced by sloping terrain $\left(\omega_{T}\right)$ was considered and computed as

$\omega_{T}=-\rho_{S} g \boldsymbol{V} \cdot \nabla h$,

where $h$ is the smoothed terrain height, $g$ is the gravitational acceleration, and $\rho_{S}$ is the air density at lower boundary (Doswell et al, 1998). The vertical velocity induced by friction $\left(\omega_{F}\right)$ was also considered, and can be computed, following Holton (1992, sect. 5.3), as

$\omega_{F}=-\rho_{S} g \varsigma_{g}\left(\frac{K_{m}}{2 f}\right)^{1 / 2}$,

where $\zeta_{\mathrm{g}}$ is geostrophic vorticity at the lower boundary, $f$ the Coriolis parameter, $K_{m}$ the eddy viscosity coefficient, which can be obtained through

$D_{e}=2 \pi\left(\frac{K_{m}}{2 f}\right)^{1 / 2}$,

where $D_{e}$ is the depth of Ekman layer, assumed to be the height of $925 \mathrm{hPa}$ layer here. From Eqs. (4) and (5) we obtained the vertical velocity at the lower boundary $\left(\omega_{1}\right)$ as

$\omega_{1}=\omega_{T}+\omega_{F}$.

Various terms of the apparent heat source $Q_{1}$ and apparent moisture sink $Q_{2}$ were also computed on the $1^{\circ} \times 1^{\circ}$ latitude/longitude grid $\left(103^{\circ}-125^{\circ} \mathrm{E}, 23^{\circ}-35^{\circ} \mathrm{N}\right)$. To better understand the development of the MCS, averaged values within $5^{\circ} \times 5^{\circ}$ boxes centered at the system's geometric center (Fig. 6a, c.f., Fig. 1) at different
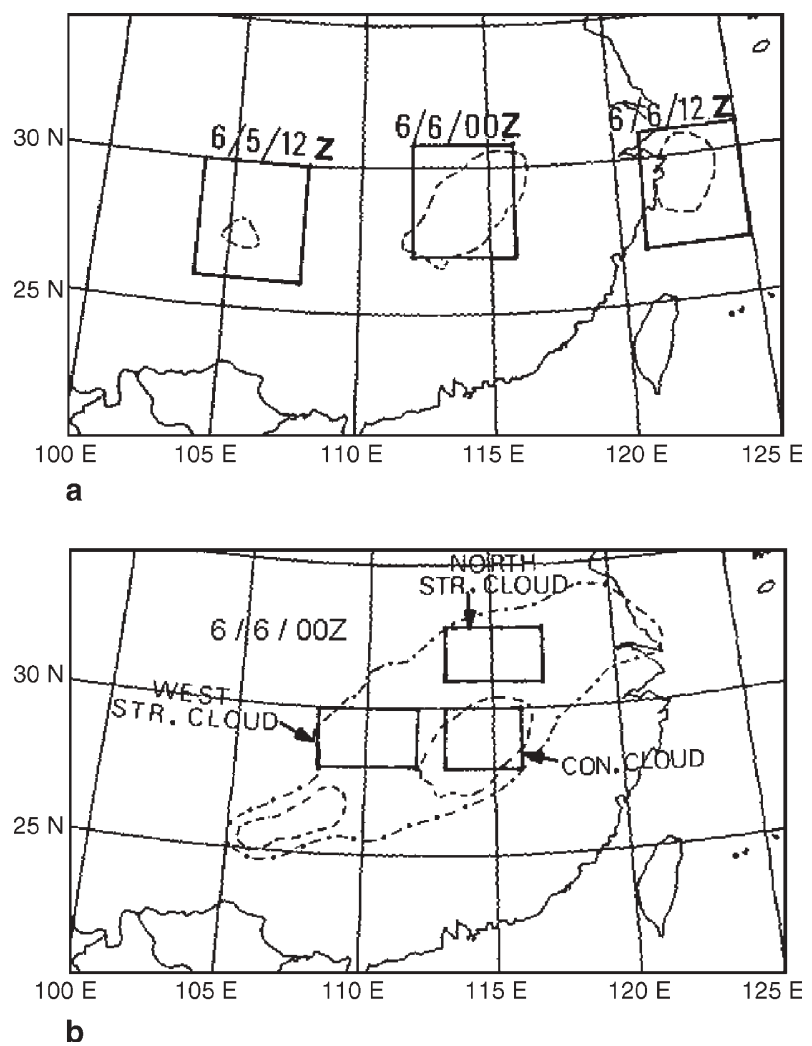

Fig. 6. Rectangular boxes used to compute averaged values of various meteorological parameters; a $5^{\circ} \times 5^{\circ}$ latitude/longitude boxes moving with the MCS from 1200 UTC June 5 to 1200 UTC June 6 at 12-h intervals; b A $3^{\circ}$ latitude $\times 4^{\circ}$ longitude box $\left(28^{\circ}-30^{\circ} \mathrm{N}, 113^{\circ}-116^{\circ} \mathrm{E}\right)$ covering the convective clouds and two $3^{\circ}$ latitude $\times 5^{\circ}$ longitude boxes covering the northern $\left(31^{\circ}-33^{\circ} \mathrm{N}, 113^{\circ}-\right.$ $\left.117^{\circ} \mathrm{E}\right)$ and western $\left(28^{\circ}-30^{\circ} \mathrm{N}, 108^{\circ}-112^{\circ} \mathrm{E}\right)$ stratiform clouds at 0000 UTC June 6

levels were computed to obtain their vertical profiles and 12-h tendencies. As an aid to the discussion of the relationship between cloud characteristics and $Q_{1}$ and $Q_{2}$, smaller rectangular boxes were also used to compute mean values at the MCS's mature stage at 0000 UTC June 6 (Fig. 6b). These boxes covered the area of convective clouds $\left(28^{\circ}-30^{\circ} \mathrm{N}, 113^{\circ}-116^{\circ} \mathrm{E}\right)$ and two areas of stratiform clouds to the north (at $31^{\circ}-33^{\circ} \mathrm{N}, 113^{\circ}-117^{\circ} \mathrm{E}$ ) and west (at $28^{\circ}-$ $30^{\circ} \mathrm{N}, 108^{\circ}-112^{\circ} \mathrm{E}$ ) of the main convection, respectively (c.f., Fig. 2c).

\section{Case diagnosis}

\subsection{Height, wind, and thermal structure}

After scale separation using the method discussed in Sect. 3.1, the geopotential heights at 
(a) $199206 / 0512 \mathrm{Z} 200 \mathrm{hPa}$ Meso Height (gpm)

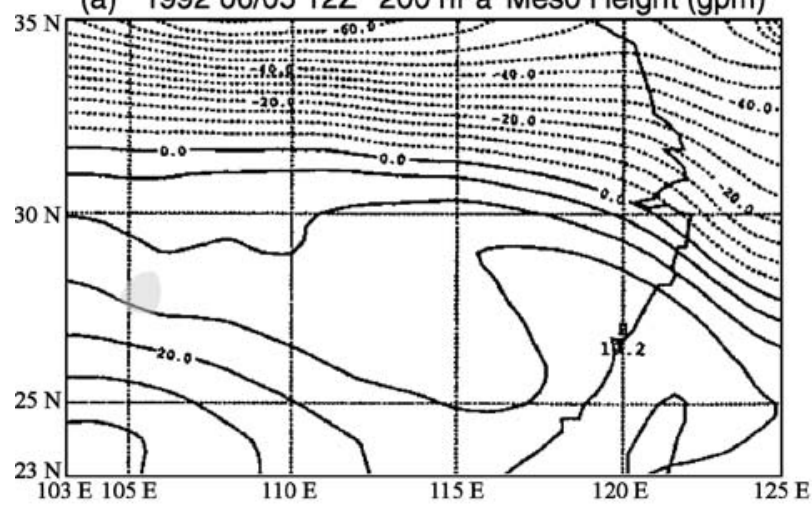

(c) $199206 / 0612 \mathrm{Z} 200 \mathrm{hPa}$ Meso Height (gpm)

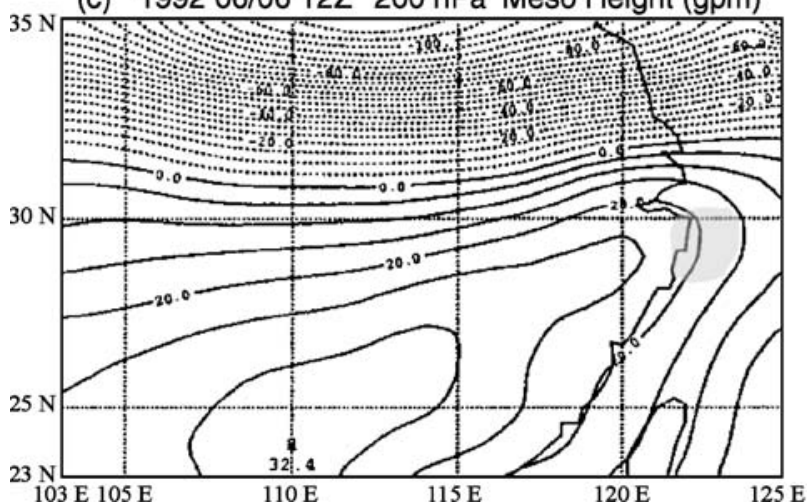

(e) $199206 / 0512 \mathrm{Z} 200 \mathrm{hPa}$ Meso Wind (kt)

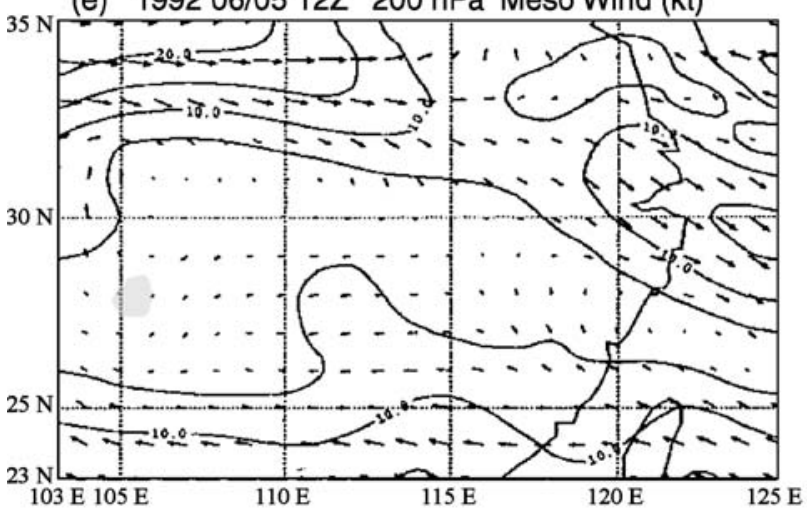

(g) $199206 / 0612 Z 200 \mathrm{hPa}$ Meso Wind (kt)

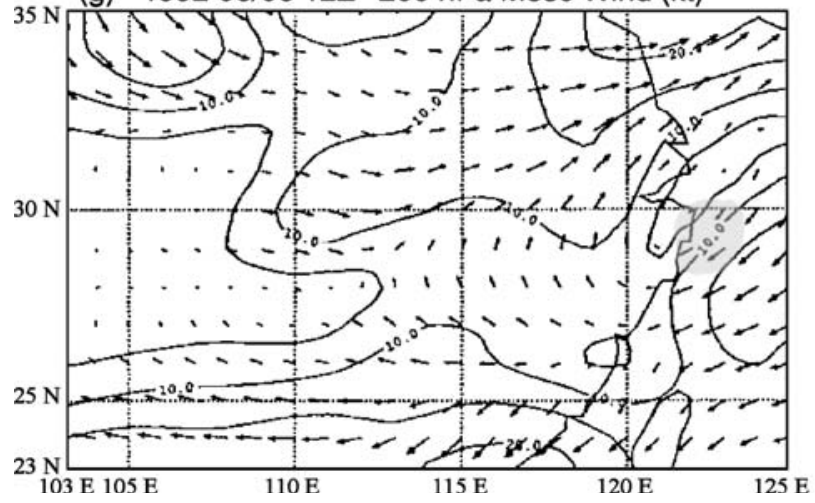

(b) $199206 / 0600 \mathrm{Z} 200 \mathrm{hPa}$ Meso Height (gpm)

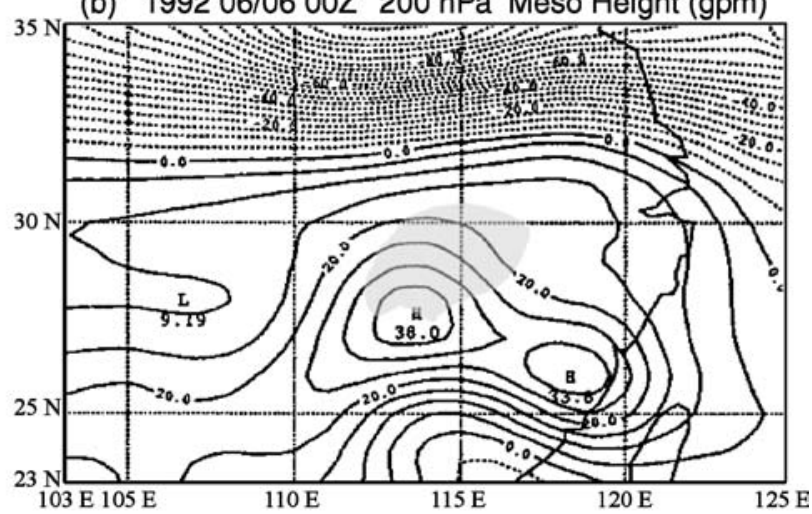

(d) $199206 / 0600 \mathrm{Z} 200 \mathrm{hPa}$ Total Height (gpm)

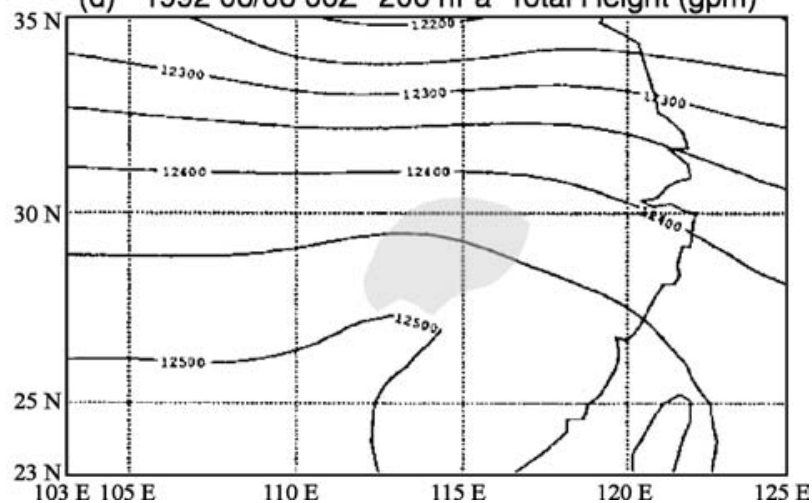

(f) 1992 06/06 00Z $200 \mathrm{hPa}$ Meso Wind (kt)

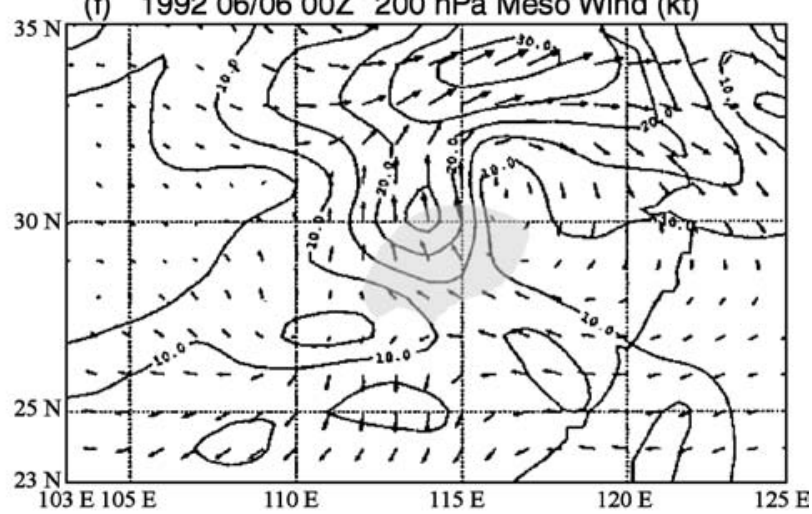

(h) $199206 / 0612 Z 200 \mathrm{hPa}$ Total Wind (kt)

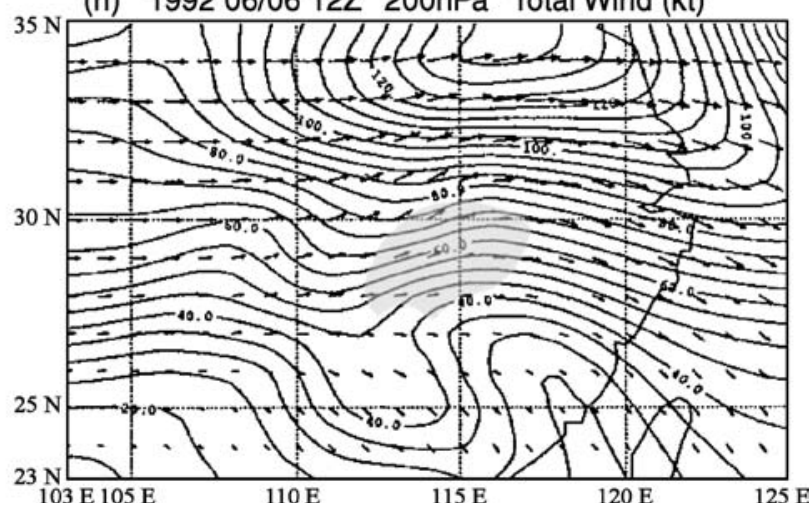


$200 \mathrm{hPa}$ for the area of $103^{\circ}-125^{\circ} \mathrm{E}, 23^{\circ}-35^{\circ} \mathrm{N}$ are presented in Fig. 7a-d. At 1200 UTC June 5, or the developing stage of the MCS, no significant mesoscale feature existed when the MCS initiated near $28^{\circ} \mathrm{N}, 104^{\circ} \mathrm{E}$ (Fig. 7a). However, a strong mesohigh established as the MCS reached the mature stage at 0000 UTC June 6, with a central value of $+38 \mathrm{gpm}$ (Fig. $7 \mathrm{~b}$ ). At 1200 UTC June 6, the MCS was dissipating and had just moved offshore of southeastern China, and the associated upper level mesohigh had weakened significantly (Fig. 7c). The total (mesoscale plus macroscale) height field was in good agreement with the subjective analysis (not shown), and indicated nearly no ridge-trough system with relatively straight contours at 0000

(a) 1992 06/05 $12 Z 300 \mathrm{hPa}$ Meso Temp (deg C)

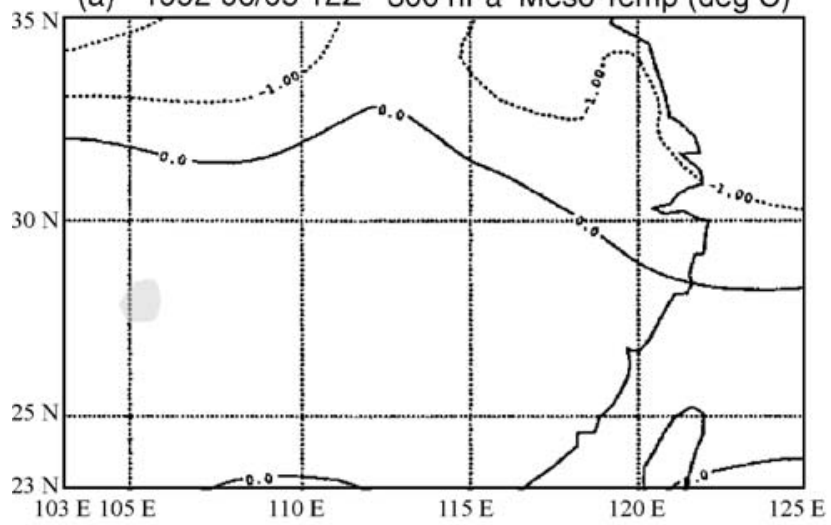

(c) 1992 06/06 $12 \mathrm{Z} 300 \mathrm{hPa}$ Meso Temp (deg C)

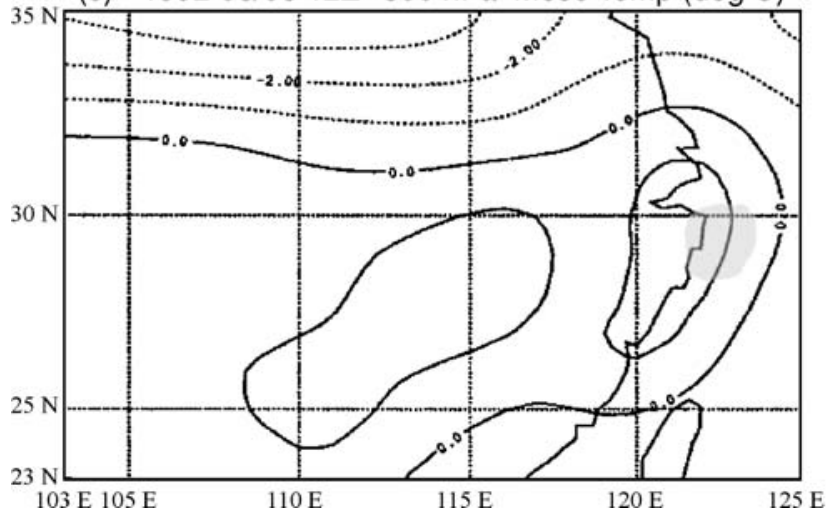

UTC, June 6, except for a weak ridge extending toward the southern flank of the MCS from the southwest (Fig. 7d). Since this ridge did not exist both $12 \mathrm{~h}$ before and after nor did it appear in the macroscale field, it was linked to the mesohigh, which was produced largely by the MCS itself.

The 200-hPa mesoscale wind field at 1200 UTC June 5 (Fig. 7e) similarly showed weak winds close to the developing MCS, but a strong anticyclonic vortex was generated with a center near $31^{\circ} \mathrm{N}$, $116^{\circ} \mathrm{E}$ at 0000 UTC June 6 (Fig. 7f). The wind speed was strong to the north, west, and also to the south of the vortex center, with peak values exceeding 30, 25, and $15 \mathrm{kts}$, respectively. The strengthening of the wind east of the vortex, however, was less. When the MCS weakened $12 \mathrm{~h}$ later,

(b) 1992 06/06 00Z $300 \mathrm{hPa}$ Meso Temp (deg C)

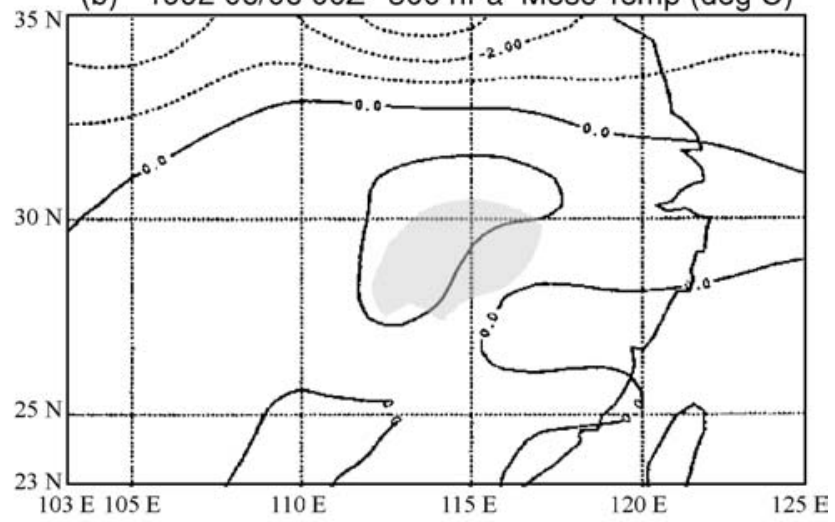

(d) 1992 06/06 00Z $300 \mathrm{hPa}$ Total Temp (deg C)

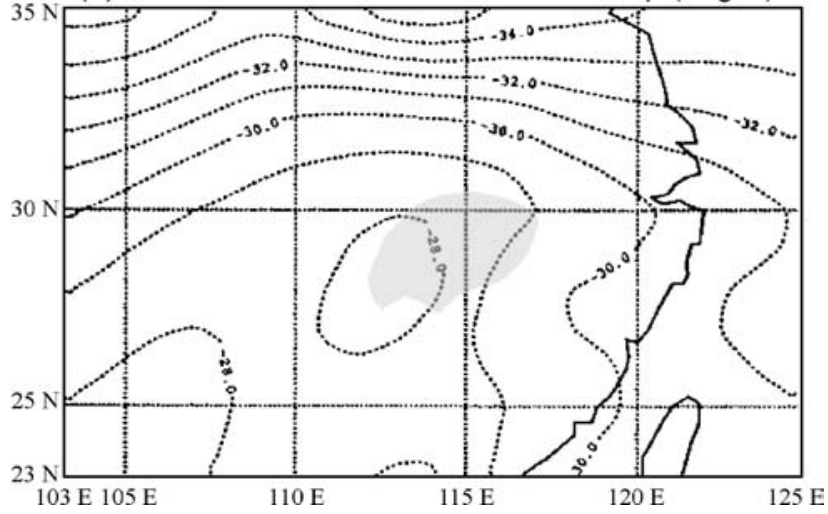

Fig. 8. 300-hPa temperature $\left({ }^{\circ} \mathrm{C}\right)$ after scale separation. Mesoscale temperature field at a 1200 UTC June 5, b 0000 UTC June 6, and c 1200 UTC June 6; d total temperature at 0000 UTC June 6. Contour intervals are $1{ }^{\circ} \mathrm{C}$, with dashed lines indicating negative values. Shadings indicate regions of the MCS with cloud-top temperature below $-52^{\circ} \mathrm{C}$

Fig. 7. 200-hPa geopotential height (gpm; a-d) and wind fields (kts; e-h) after scale separation. Mesoscale height field at a 1200 UTC June 5, b 0000 UTC June 6, and c 1200 UTC June 6; d total height at 0000 UTC June 6. Contour intervals are $5 \mathrm{gpm}$ in a to $\mathbf{c}$ and $50 \mathrm{gpm}$ in $\mathbf{d}$, with dashed lines indicating negative values. Panels $\mathbf{e}$ to $\mathbf{h}$ are the same as $\mathbf{a}$ to $\mathbf{d}$, except for wind (arrows and isotachs). Contour intervals for isotachs are $5 \mathrm{kts}$, and arrow lengths are proportional to wind speed. Shadings indicate regions of the MCS with cloud-top temperature below $-52{ }^{\circ} \mathrm{C}$ 
the anticyclonic circulation was still evident but its intensity reduced (Fig. 7g). By comparing Fig. 7b, $\mathrm{d}$ and $\mathrm{f}$, it is clear that winds with strong northward components were located immediately to the north of the upper level mesohigh, and was largely ageostrophic. Obviously, the establishment of the upper-level mesohigh enhanced the north-south height gradient, and produced northward ageostrophic flow through geostrophic adjustment. Then, through Coriolis acceleration of the northward-moving flow, the westerlies to the north of the MCS also strengthened. Because of the presence of the mesoscale anticyclone, the westerlies were stronger to the north and weaker to the south of the MCS in the objectively analyzed total wind field at 0000 UTC June 6 (Fig. 7h). Figure 7h also clearly illustrates the upper-level diffluent flow pattern, which was produced by the northward ageostrophic winds (Fig. 7f) and can be seen in the subjective analysis as well (Fig. 3b).

At $300 \mathrm{hPa}$, the mesoscale temperature gradient was quite weak everywhere in southern China at 1200 UTC June 5 (Fig. 8a). However, a region with higher temperature, at least $1-2{ }^{\circ} \mathrm{C}$ warmer than the surrounding area, appeared near the MCS at 0000 UTC June 6, and remained evident through 1200 UTC (Fig. 8b,c). This feature enhanced the thermal ridge and contributed to the appearance of a warm core $\left(>-28^{\circ} \mathrm{C}\right)$ near the MCS in the total temperature field at 0000 UTC June 6 (Fig. 8d). At 1200 UTC June 6, the region near the MCS in the total temperature field was still warmer, but no closed isotherm could be analyzed (not shown). A similar warm core structure with comparable strength could also be seen at $500 \mathrm{hPa}$, but will not be shown here.

Figure 9a depicts the vertical profiles of mesoscale geopotential heights averaged inside the $5^{\circ} \times 5^{\circ}$ boxes (Fig. 6a) at the three synoptic times from 1200 UTC June 5 to 1200 UTC June 6. From developing to mature stage, the two curves ( $\mathrm{A}$ and $\mathrm{B}$ ) changed very little below $400 \mathrm{hPa}$, but further up the height increased significantly over the 12 -h period. The increase was more than $10 \mathrm{gpm}$ at $200 \mathrm{hPa}$ and above, where the averaged $5^{\circ} \times 5^{\circ}$ mesoscale geopotential height reached 25-28 gpm. At 1200 UTC June 6 (curve C), the geopotential height also increased by about 5-10 gpm below $350 \mathrm{hPa}$, but decreased above $350 \mathrm{hPa}$ (especially above $200 \mathrm{hPa}$ ), indicating the weakening of the upper-level mesohigh.
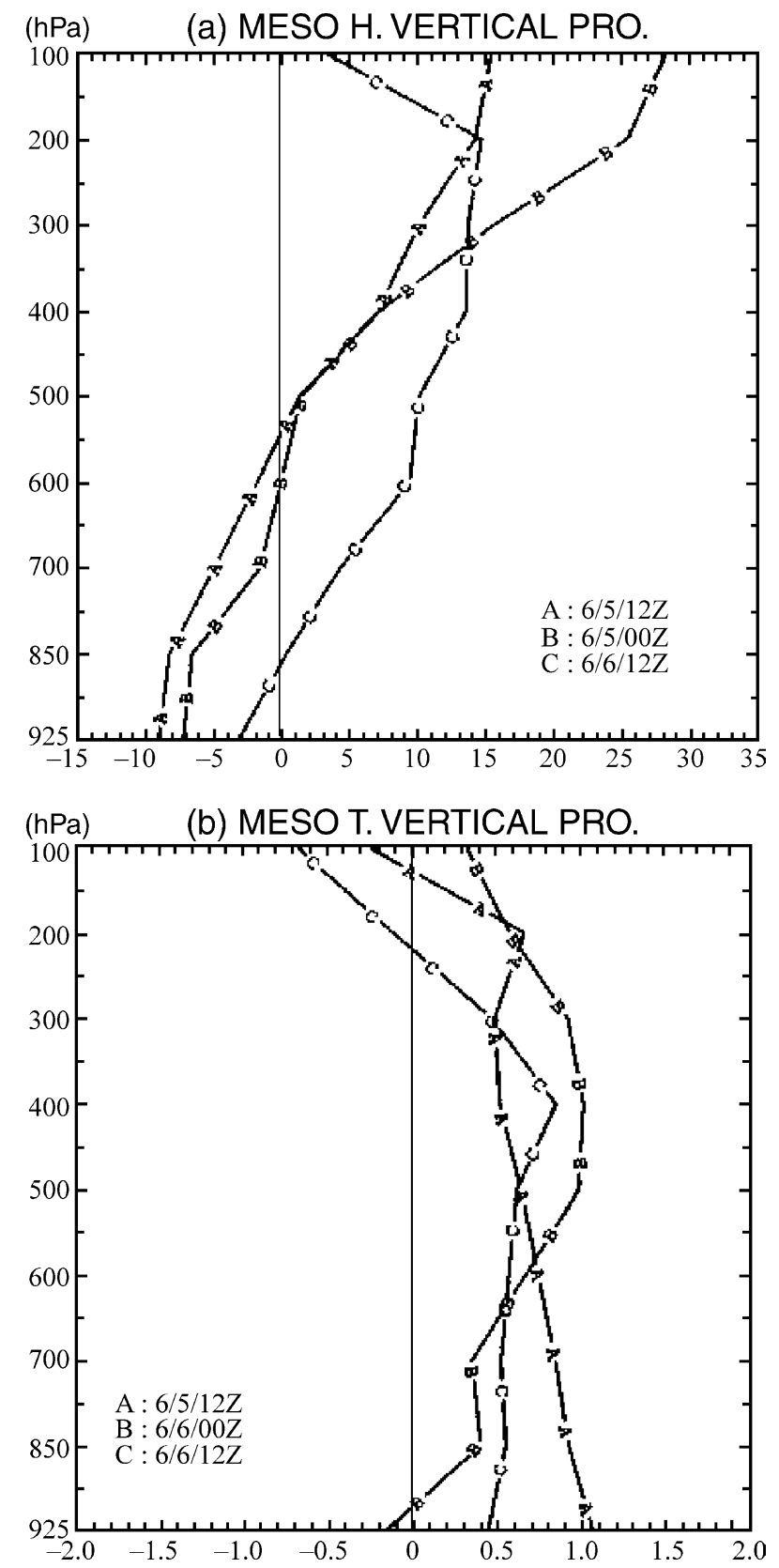

Fig. 9. Vertical profiles of mesoscale a geopotential heights (gpm), and $\mathbf{b}$ temperature $\left({ }^{\circ} \mathrm{C}\right)$ averaged over $5^{\circ} \times 5^{\circ}$ boxes at the locations of the MCS (as shown in Fig. 6a) for 1200 UTC June 5 (curve A), and 0000 UTC (curve B) and 1200 UTC (curve C) June 6

Vertical profiles of $5^{\circ} \times 5^{\circ}$ mean mesoscale temperature show that a warm perturbation of about $1{ }^{\circ} \mathrm{C}$ existed in the lower to middle troposphere at 1200 UTC June 5 (curve A, Fig. 9b). Twelve hours later, as significant warming associated with latent heat release occurred between 600 and $250 \mathrm{hPa}$, the warming at lower levels weakened, especially at $925 \mathrm{hPa}$ (curve B). At 
the dissipating stage, both the warming aloft and cooling below weakened (curve C). There was also evident cooling above $400 \mathrm{hPa}$, most likely due to radiative cooling effects.

\subsection{Divergence, relative vorticity, and vertical motion}

Results for the $850-\mathrm{hPa}$ and $200-\mathrm{hPa}$ divergence fields after scale separation are presented in Fig. 10. At 1200 UTC June 5, near the developing MCS there was weak mesoscale lowlevel convergence of about $-1.5 \times 10^{-5} \mathrm{~s}^{-1}$ (Fig. 10a), while upper-level divergence less than about $1.0 \times 10^{-5} \mathrm{~s}^{-1}$ was also present (Fig. 10e). As the MCS matured at 0000 UTC June 6 , both the low-level convergence and upper-level divergence intensified dramatically. The $850-\mathrm{hPa}$ convergence was strongest over the southern and eastern quadrants of the convec- tive area with cloud-top temperature lower than $-52{ }^{\circ} \mathrm{C}$ (shaded), and reached a magnitude of $-4.0 \times 10^{-5} \mathrm{~s}^{-1}$ (Fig. 10b). West of the deep convection, closer to the region of surface mesohigh, on the other hand, strong divergence $\left(>3.0 \times 10^{-5} \mathrm{~s}^{-1}\right)$ dominated. The $200-\mathrm{hPa}$ divergence at 0000 UTC June 6 was also evident and exceeded $3.0 \times 10^{-5} \mathrm{~s}^{-1}$ directly above the convection (Fig. 10f). At 1200 UTC June 6, the 850-hPa convergence had weakened significantly, with a peak value of about $-2.0 \times 10^{-5} \mathrm{~s}^{-1}$ (Fig. 10c). At $200 \mathrm{hPa}$ there was mostly weak convergence near the MCS, replacing the earlier divergence (Fig. 10g).

The $850-\mathrm{hPa}$ macroscale divergence field at 0000 UTC June 6 showed no significant feature, with only weak convergence or near-zero values near the MCS (Fig. 10d). At $200 \mathrm{hPa}$, however, divergence existed over much of the southern China (Fig. 10h). The divergence had

\section{(a) 1992 06/05 $12 \mathrm{Z} 850 \mathrm{hPa}$ Meso Div $\left(10^{-6} \mathrm{~s}^{-1}\right)$}

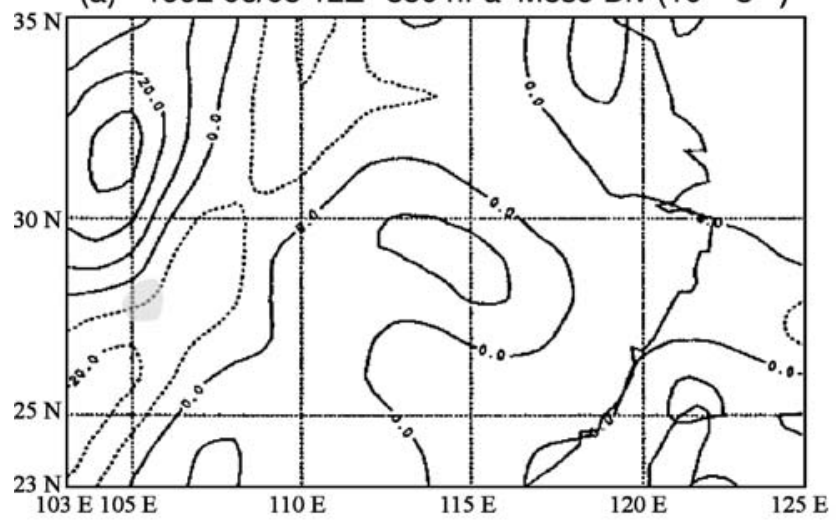

(c) $199206 / 0612 Z 850 \mathrm{hPa}$ Meso Div $\left(10^{-6} \mathrm{~s}^{-1}\right)$

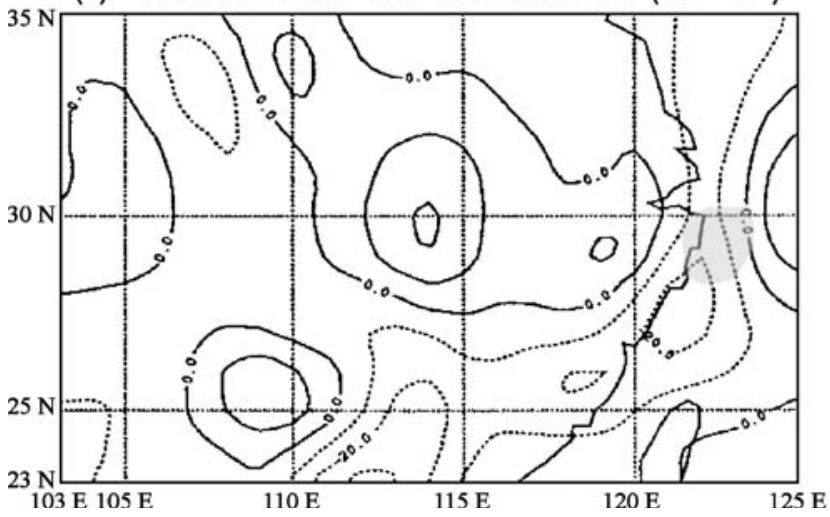

(b) $199206 / 0600 \mathrm{Z} 850 \mathrm{hPa}$ Meso Div $\left(10^{-6} \mathrm{~s}^{-1}\right)$

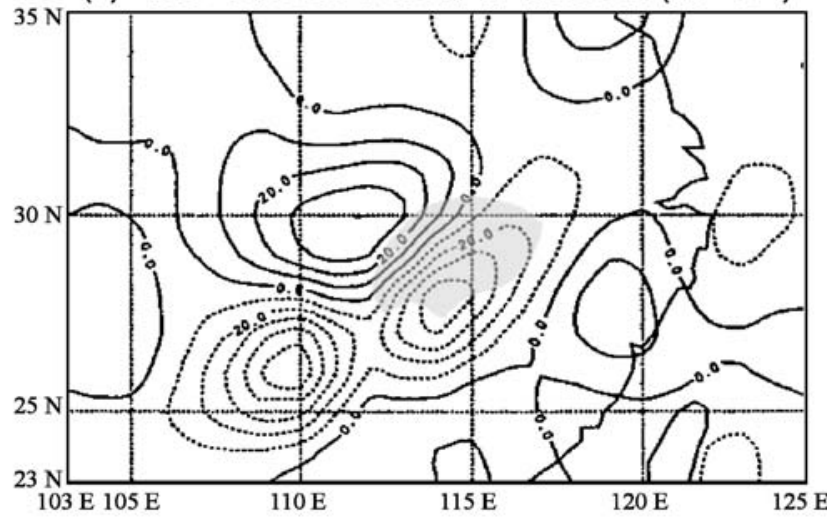

(d) $199206 / 0600 \mathrm{Z} 850 \mathrm{hPa}$ Macro Div $\left(10^{-6} \mathrm{~s}^{-1}\right)$

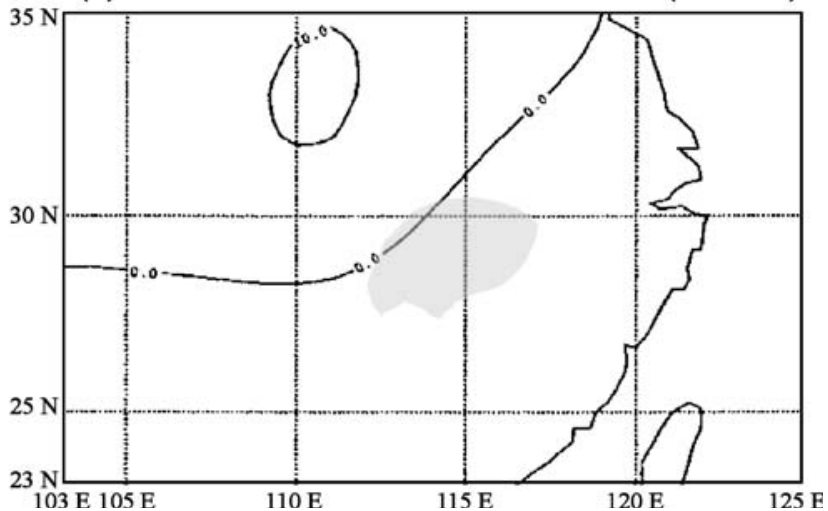

Fig. 10. $850-\mathrm{hPa}$ and $200-\mathrm{hPa}$ divergence $\left(10^{-6} \mathrm{~s}^{-1}\right)$ after scale separation. $850-\mathrm{hPa}$ mesoscale divergence at a $1200 \mathrm{UTC}$ June 5, b 0000 UTC June 6, and c 1200 UTC June 6; d 850-hPa macroscale divergence at 0000 UTC June 6 . Panels e to h are the same as a to d, except for $200-\mathrm{hPa}$. Contour intervals are $10 \times 10^{-6} \mathrm{~s}-1$, with dashed lines indicating negative values. Shadings indicate regions of the MCS with cloud-top temperature below $-52{ }^{\circ} \mathrm{C}$ 
(e) $199206 / 0512 \mathrm{Z} 200 \mathrm{hPa}$ Meso Div $\left(10^{-6} \mathrm{~s}^{-1}\right)$

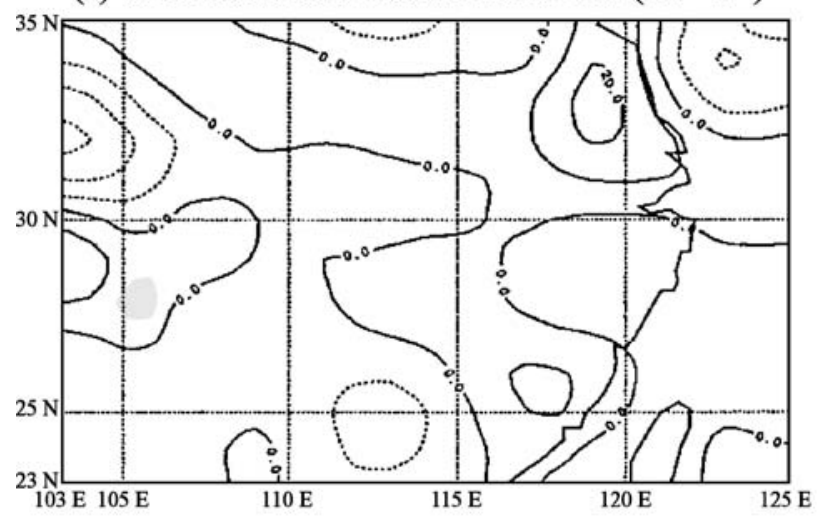

(g) $199206 / 0612 \mathrm{Z} 200 \mathrm{hPa}$ Meso Div $\left(10^{-6} \mathrm{~s}^{-1}\right)$

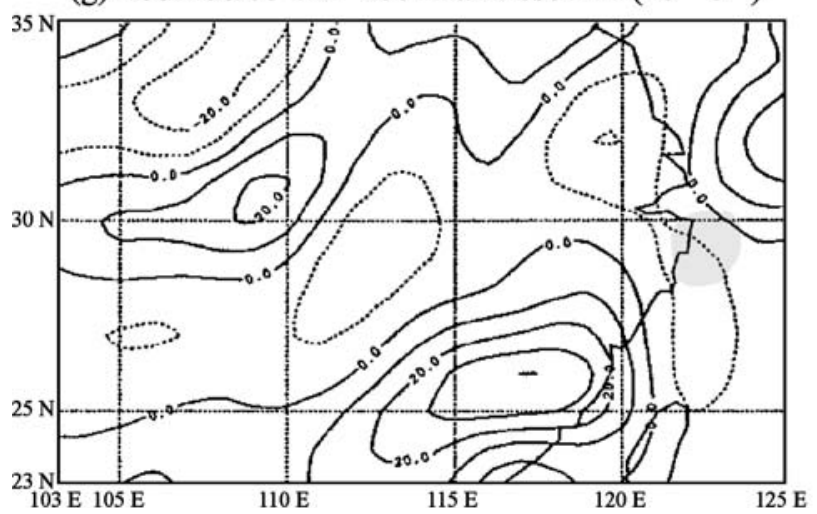

(f) $199206 / 0600 \mathrm{Z} 200 \mathrm{hPa}$ Meso Div $\left(10^{-6} \mathrm{~s}^{-1}\right)$

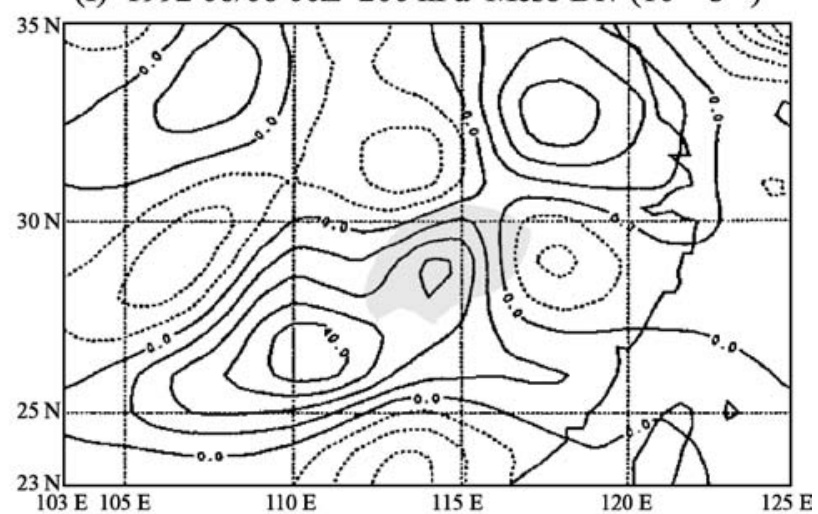

(h) $199206 / 0600 \mathrm{Z} 200 \mathrm{hPa}$ Macro Div $\left(10^{-6} \mathrm{~s}^{-1}\right)$

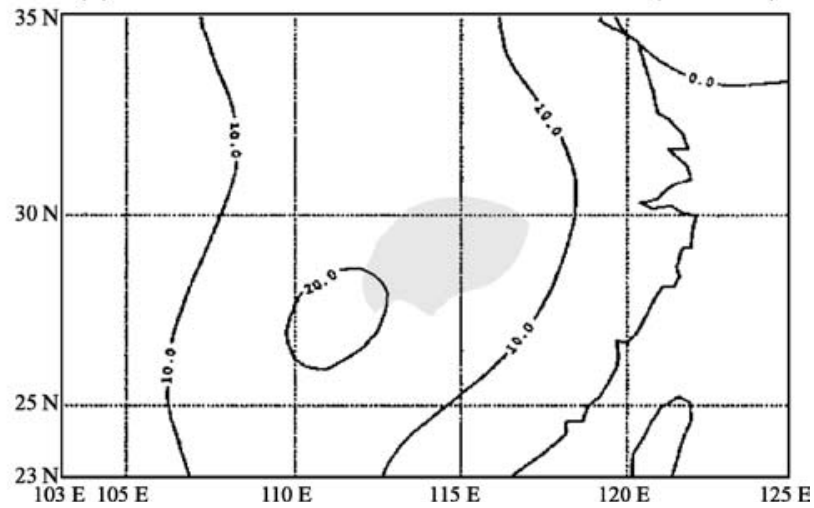

Fig. 10 (continued)

a maximum of $-2.0 \times 10^{-5} \mathrm{~s}^{-1}$ just to the southwest of the deep convection, and was stronger than $-1.0 \times 10^{-5} \mathrm{~s}^{-1}$ over the MCS and adjacent areas. Thus, the total (mesoscale and macroscale) divergence near the MCS at $200 \mathrm{hPa}$ would be both occupying a larger area and stronger than indicated by only the mesoscale field. Since no significant large-scale wave system existed in Fig. 7d, the divergence over a vast area in Fig. 10h was likely associated with the MCS itself. That is, effects of the MCS were already present over the surrounding area in the macroscale divergence field at the mature stage.

The $850-\mathrm{hPa}$ and $200-\mathrm{hPa}$ mesoscale relative vorticity fields corresponding to Fig. 10 are presented in Fig. 11. At 1200 UTC June 5, cyclonic (positive) vorticity with maximum value over $4.0 \times 10^{-5} \mathrm{~s}^{-1}$ appeared near the center of the deep convection at $850 \mathrm{hPa}$ (Fig. 11a), but at $200 \mathrm{hPa}$ only very weak anticyclonic (negative) vorticity was found near the MCS (Fig. 11e). When the MCS matured, the low-level cyclonic vorticity further enhanced to nearly $5.0 \times$ $10^{-5} \mathrm{~s}^{-1}$ and concentrated at the region of most intense convection (Fig. 11b). The 200-hPa anticyclonic vorticity also intensified rapidly, and reached a maximum of about $-1.0 \times 10^{-4} \mathrm{~s}^{-1}$ immediately to the northeast of the MCS. The location of the maximum agreed well with the anticyclonic circulation observed in the mesoscale wind field (Figs. 7f and 11f). Later at the dissipating stage, both the low-level cyclonic vorticity and upper-level anticyclonic vorticity associated with the MCS weakened considerably (Fig. 11c, g).

The macroscale vorticity field at $850 \mathrm{hPa}$ indicated weak positive vorticity of about $1.5 \times 10^{-5} \mathrm{~s}^{-1}$ near the MCS at the mature stage (Fig. 11d). At $200 \mathrm{hPa}$, in contrast, relatively strong anticyclonic vorticity was present over a large area, with a central value in excess of $-6 \times 10^{-5} \mathrm{~s}^{-1}$ to the north-northeast of the MCS (Fig. 11h). The fact that the center was found slightly downwind from the MCS was 
(a) $199206 / 0512 \mathrm{Z} 850 \mathrm{hPa}$ Meso Vort $\left(10^{-6} \mathrm{~s}^{-1}\right)$

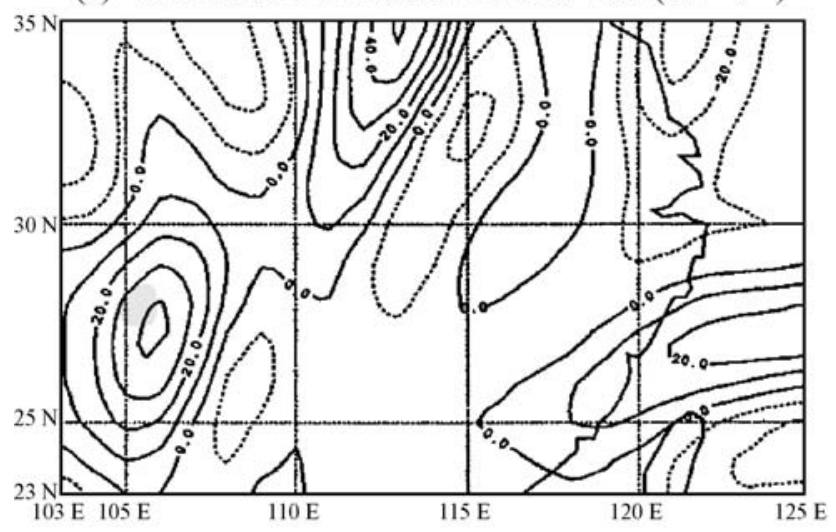

(c) $199206 / 0612 \mathrm{Z} 850 \mathrm{hPa}$ Meso Vort $\left(10^{-6} \mathrm{~s}^{-1}\right)$

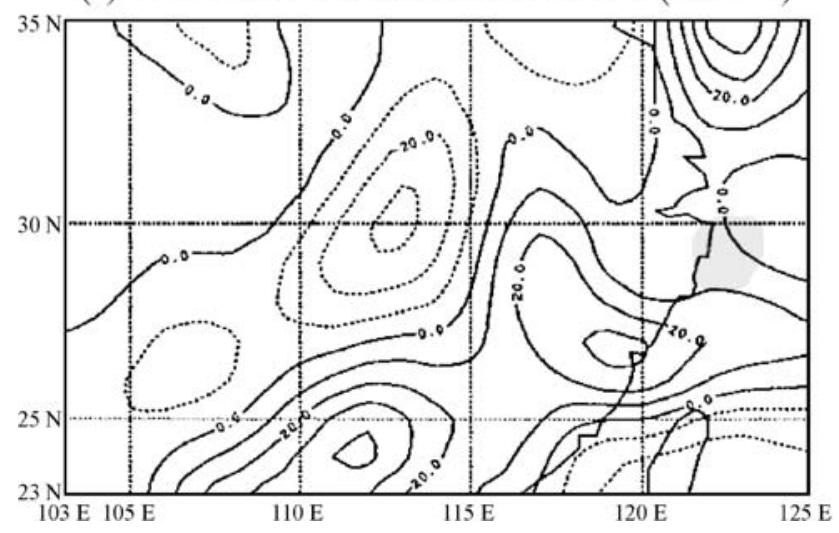

(b) 1992 06/06 00Z $850 \mathrm{hPa}$ Meso Vort $\left(10^{-6} \mathrm{~s}^{-1}\right)$

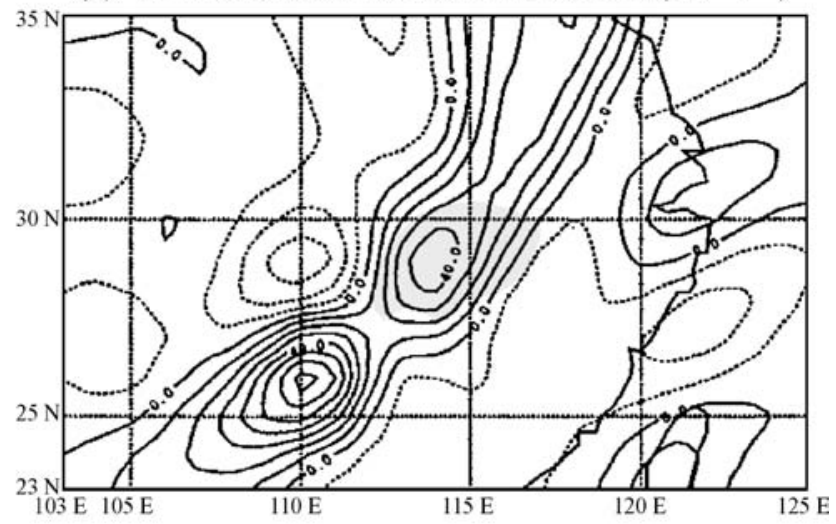

(d) $199206 / 0600 \mathrm{Z} 850 \mathrm{hPa}$ Macro Vort $\left(10^{-6} \mathrm{~s}^{-1}\right)$

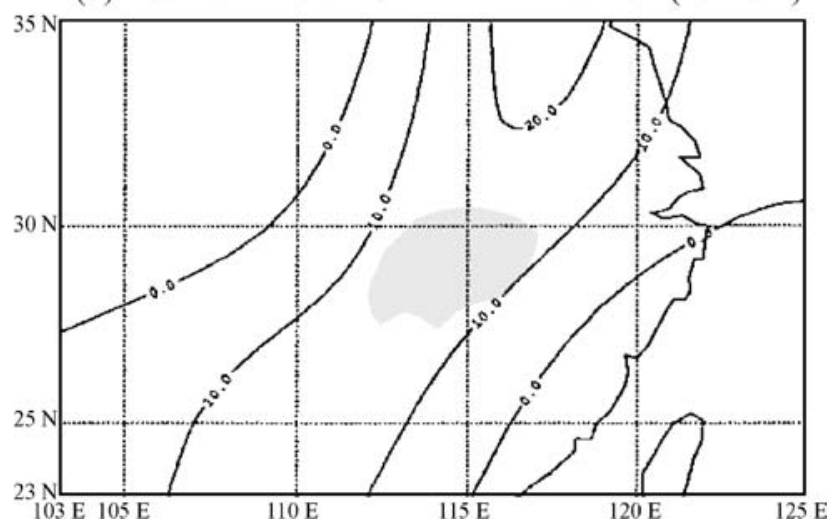

Fig. 11. Same as Fig. 10, except for $850-\mathrm{hPa}(\mathrm{a}-\mathrm{d})$ and $200-\mathrm{hPa}(\mathrm{e}-\mathrm{h})$ relative vorticity $\left(10^{-6} \mathrm{~s}^{-1}\right)$. Contour intervals are also $10 \times 10^{-6} \mathrm{~s}^{-1}$

likely due to the advection by strong upperlevel winds. Nevertheless, clear indication for the influence of the MCS also appeared in the macroscale relative vorticity field at $200 \mathrm{hPa}$ as the MCS matured. At $500 \mathrm{hPa}$, the magnitude of relative vorticity was considerably weaker than at both 850 and $200 \mathrm{hPa}$, reaching only about $-1.5 \times 10^{-5} \mathrm{~s}^{-1}$ at 0000 UTC and $-1.0 \times 10^{-5} \mathrm{~s}^{-1}$ at 1200 UTC June 6 , respectively (not shown). Therefore, the mid-level cyclonic vortex often observed in cases over the North America was not apparent in this case.

The 500-hPa mesoscale vertical velocity at the developing stage (Fig. 12a) suggests that strong upward motion (negative values) was located about $5^{\circ}$ northeast of the MCS. Only relatively weak ascent, roughly $-5 \mathrm{hPah}^{-1}$, existed near the MCS. At 0000 UTC June 6, upward motion over the MCS strengthened rapidly as expected, reaching a maximum of $-32 \mathrm{hPah}^{-1}$ at the southern flank of the deep convective clouds
(Fig. 12b). To the northwest of the convection, over the area of stratiform clouds, there was strong sinking motion at $500 \mathrm{hPa}$, with a maximum of $24 \mathrm{hPah}^{-1}$. At the dissipating stage (Fig. 12c), the peak value of ascent remained quite strong $\left(<-24 \mathrm{hPah}^{-1}\right)$ but was to the southwest of the convection at coastal regions where new convective cells were developing (c.f., Fig. 2e).

At other levels in the troposphere, upward motion also dominated near the MCS and downward motion to the northwest in the mature stage (not shown), but not as strong as at $500 \mathrm{hPa}$. As expected, the values at lower levels were stronger than the upper-level ones at developing stage, and the opposite was true at dissipating stage. In the macroscale vertical velocity field at 0000 UTC June 6, only weak upward motion was present over the MCS and surrounding areas, about 0 to $-6 \mathrm{hPah}^{-1}$ at $500 \mathrm{hPa}$ (Fig. 12d), and the values were even smaller at lower levels (not shown). 
(e) $199206 / 0512 \mathrm{Z} 200 \mathrm{hPa}$ Meso Vort $\left(10^{-6} \mathrm{~s}^{-1}\right)$

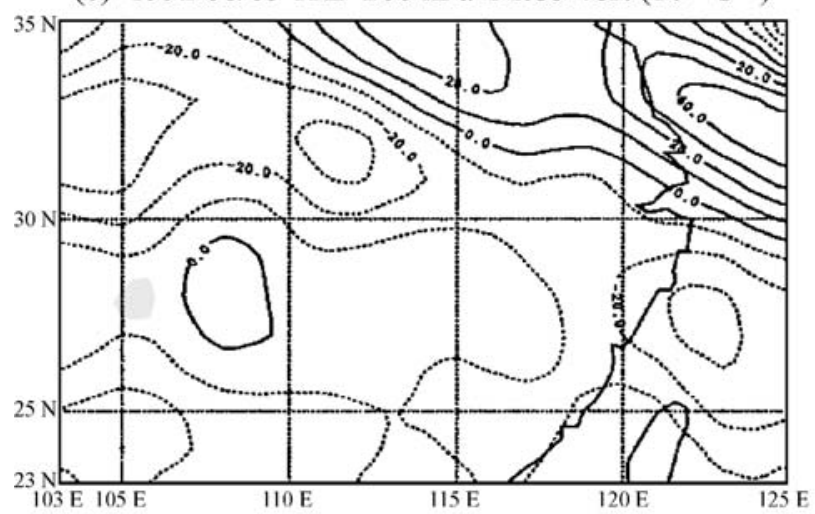

(g) 1992 06/06 $12 \mathrm{Z} 200 \mathrm{hPa}$ Meso Vort $\left(10^{-6} \mathrm{~s}^{-1}\right)$

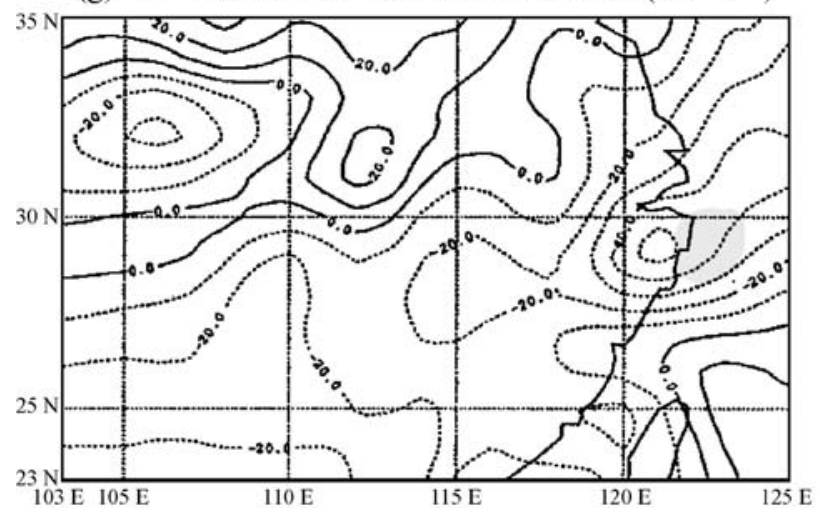

(f) 1992 06/06 00Z $200 \mathrm{hPa}$ Meso Vort $\left(10^{-6} \mathrm{~s}^{-1}\right)$

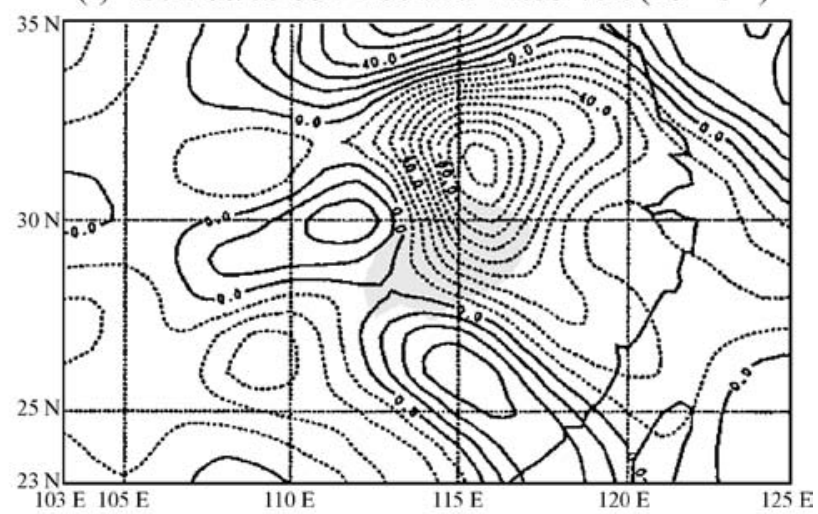

(h) $199206 / 0600 \mathrm{Z} 200 \mathrm{hPa}$ Macro Vort $\left(10^{-6} \mathrm{~s}^{-1}\right)$

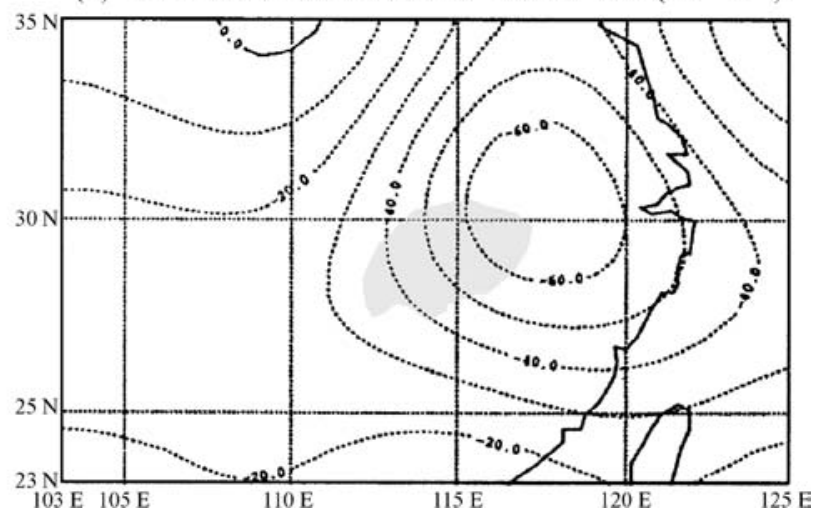

Fig. 11 (continued)

Figure 13 depicts vertical profiles of mesoscale relative vorticity, divergence, and vertical velocity averaged within the $5^{\circ} \times 5^{\circ}$ boxes between 1200 UTC June 5 and 1200 UTC June 6 (curves A to C). At all three stages, the lower troposphere was dominated by cyclonic vorticity and the upper levels by anticyclonic vorticity (Fig. 13a), consistent with Fig. 11. From developing to mature stage, the upper level anticyclonic vorticity increased significantly, especially at 200-300 hPa, while the low level cyclonic vorticity also increased (curves A and B). Lowlevel cyclonic vorticity decreased as the MCS weakened at 1200 UTC of June 6, and the layer aloft with strongest anticyclonic vorticity ascended to $200 \mathrm{hPa}$ and above. The level of zero vorticity was located near $500 \mathrm{hPa}$ at the developing and mature stages, and lowered to about $700 \mathrm{hPa}$ at the dissipating stage (Fig. 13a). It is interesting to note that the relative vorticity for the MCS environment (macroscale and mesoscale) was very weak in the mid-troposphere and the MCS occurred in the subtropical latitude with small $f$. Therefore, the vortex stretching process was unlikely to be effective enough to form a MCV, consistent with the absence of such a feature.

Vertical profiles of mesoscale divergence indicate that convergence existed at low levels with divergence aloft during the developing and mature stages of the MCS (Fig. 13b). At 1200 UTC June 5, convergence was confined to below $700 \mathrm{hPa}$, and the divergence was in the middle troposphere, maximized at $500 \mathrm{hPa}$ (curve A). Twelve hours later when the MCS reached maturity, however, significant convergence had extended from $925 \mathrm{hPa}$ all the way up to above $350 \mathrm{hPa}$, with a mean value close to $-6.0 \times 10^{-6} \mathrm{~s}^{-1}$ over the column (curve B). The divergent layer became shallower and the level of maximum divergence rose significantly to $200 \mathrm{hPa}$, while the peak value increased marginally to nearly $1.0 \times 10^{-5} \mathrm{~s}^{-1}$. At dissipating stage, upper level divergence had disappeared, and the entire column was dominated by weak to moderate convergence (curve $\mathrm{C}$ ). The vertical 
(a) $199206 / 0500 \mathrm{Z} 500 \mathrm{hPa}$ Meso Omega $\left(\mathrm{hPa} \mathrm{h}^{-1}\right)$

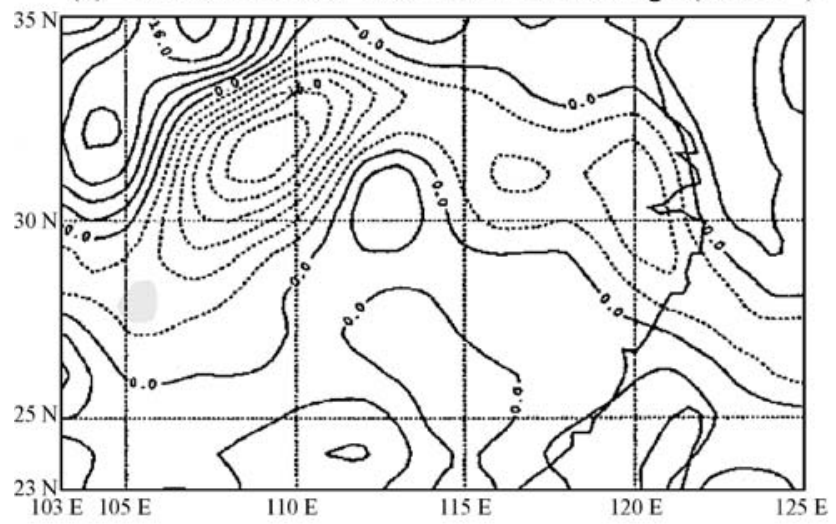

(c) 1992 06/06 $12 \mathrm{Z} 500 \mathrm{hPa}$ Meso Omega $\left(\mathrm{hPa} \mathrm{h}^{-1}\right)$

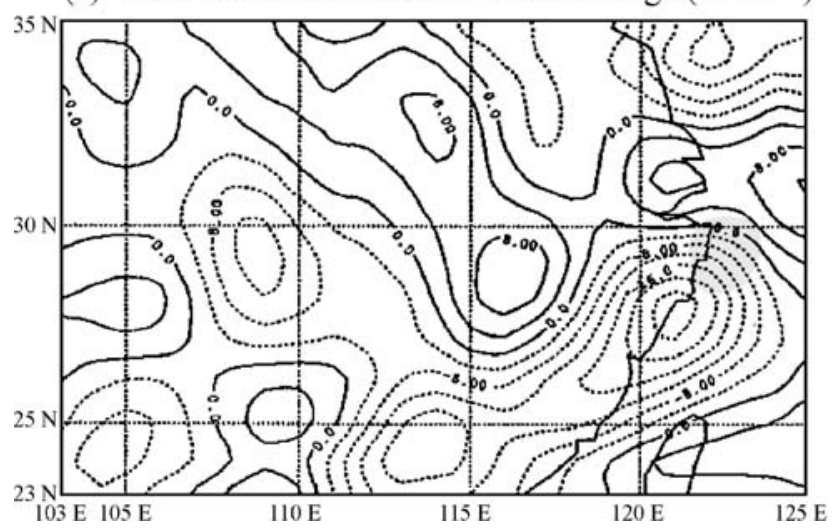

(b) $199206 / 0600 \mathrm{Z} 500 \mathrm{hPa}$ Meso Omega $\left(\mathrm{hPa} \mathrm{h}^{-1}\right)$

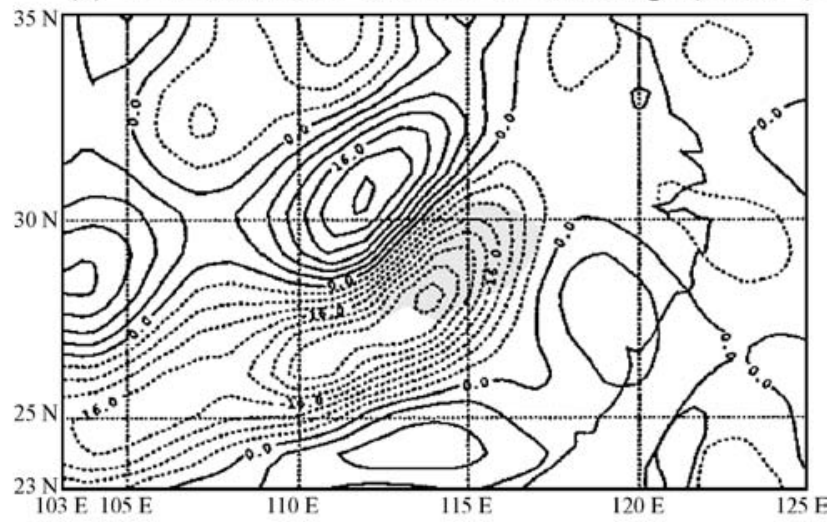

(d) 1992 06/06 00Z $500 \mathrm{hPa}$ Macro Omega $\left(\mathrm{hPa} \mathrm{h}^{-1}\right)$

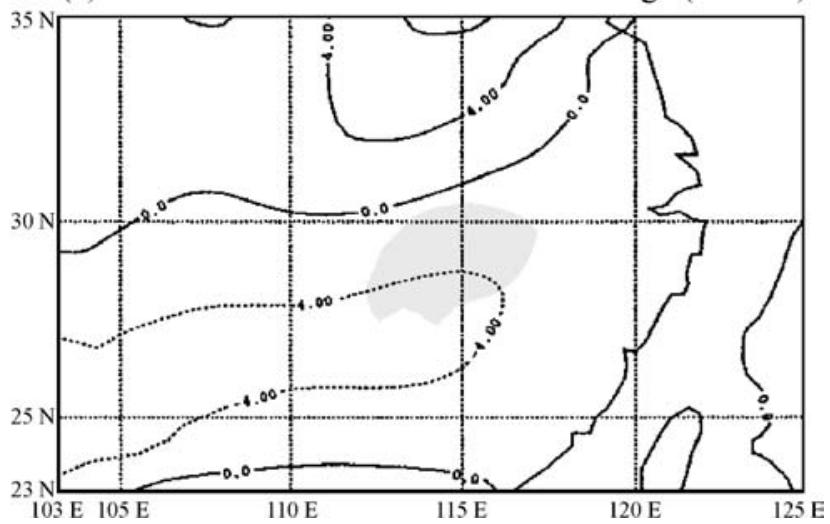

Fig. 12. 500-hPa vertical velocity $\left(\omega ; \mathrm{hPah}^{-1}\right)$ after scale separation. Mesoscale vertical velocity at a 1200 UTC June 5 , b 0000 UTC June 6, and c 1200 UTC June 6; d macroscale vertical velocity at 0000 UTC June 6. Contour intervals are $4 \mathrm{hPah}^{-1}$, with solid lines (positive) indicating sinking motion and dashed lines (negative) indicating rising motion. Shadings indicate regions of the MCS with cloud-top temperature below $-52{ }^{\circ} \mathrm{C}$

velocity profiles (Fig. 13c) reveal changes in response to the divergence field. From developing to mature stage, the upward motion not only grew stronger in peak value, from about -7.6 to $-9.3 \mathrm{hPah}^{-1}$, but its vertical extent also increased, such that the layer of strongest ascent rose from 700 to $400 \mathrm{hPa}$ (curves A and B). Thus, significant ascent from $925 \mathrm{hPa}$ to above $250 \mathrm{hPa}$ was present as the MCS matured, with intense latent heat release. Twelve hours later, the upward motion weakened to below $-3.3 \mathrm{hPa} \mathrm{h}^{-1}$ in the entire column (curve $\mathrm{C}$ ), as the divergence aloft also vanished (Fig. 13b).

\subsection{Moisture convergence, apparent heat source and apparent moisture sink}

The $850-\mathrm{hPa}$ horizontal moisture flux convergence from 1200 UTC June 5 to 1200 UTC June
6 is depicted in Fig. 14. As expected, the patterns of moisture flux convergence were very similar to the divergence field with the sign reversed (Fig. 10a-c), and to a lesser extent to the vorticity field (Fig. 11a-c). Maximum convergence near the MCS intensified from about $2 \times$ $10^{-4} \mathrm{~g} \mathrm{~kg}^{-1} \mathrm{~s}^{-1}$ at developing stage to more than $7 \times 10^{-4} \mathrm{~g} \mathrm{~kg}^{-1} \mathrm{~s}^{-1}$ at mature stage (Fig. $14 a, b)$. The largest increase was at the southern flank of the convective cloud, also the region of strongest upward motion (Fig. 12b). As the MCS matured, an area of clear moisture flux divergence, with a maximum of $-7 \times$ $10^{-4} \mathrm{~g} \mathrm{~kg}^{-1} \mathrm{~s}^{-1}$, also developed just to the northwest, consistent with the sinking motion and low level divergence. Then, the moisture flux convergence weakened at dissipating stage, to around 1 to $4 \times 10^{-4} \mathrm{~g} \mathrm{~kg}^{-1} \mathrm{~s}^{-1}$ near the MCS, along with the moisture flux divergence 

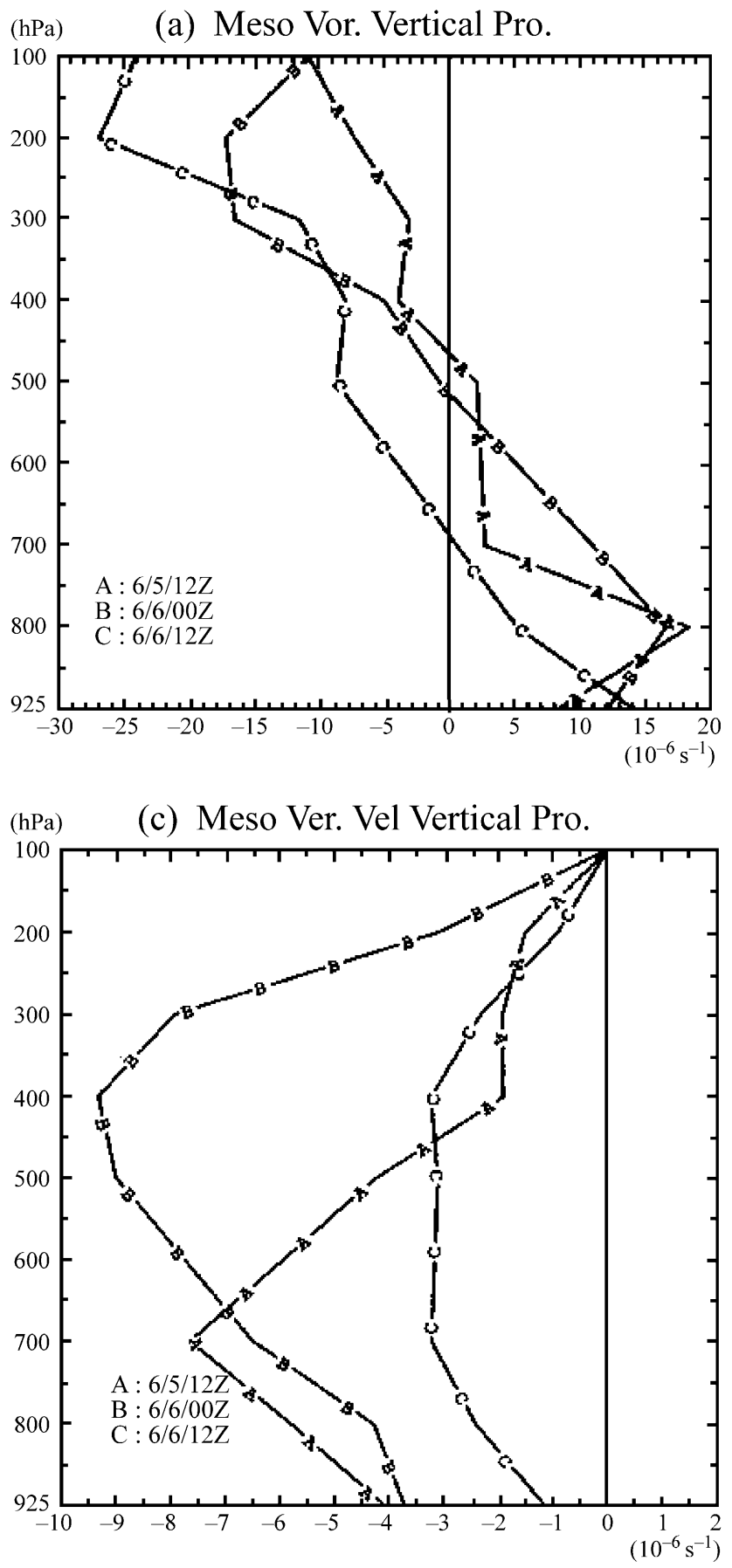

(Fig. 14c). The patterns of horizontal moisture flux convergence at $925 \mathrm{hPa}$ were nearly identical to those at $850 \mathrm{hPa}$ but somewhat weaker in values, and the magnitudes were further reduced to within $\pm 2.5 \times 10^{-4} \mathrm{~g} \mathrm{~kg}^{-1} \mathrm{~s}^{-1}$ at $700 \mathrm{hPa}$ mainly due the lower moisture content (not shown). Consistent with the moisture flux convergence, the relative humidity in the troposphere also increased near the MCS between 1200 UTC June 5 and 0000 UTC June 6, from

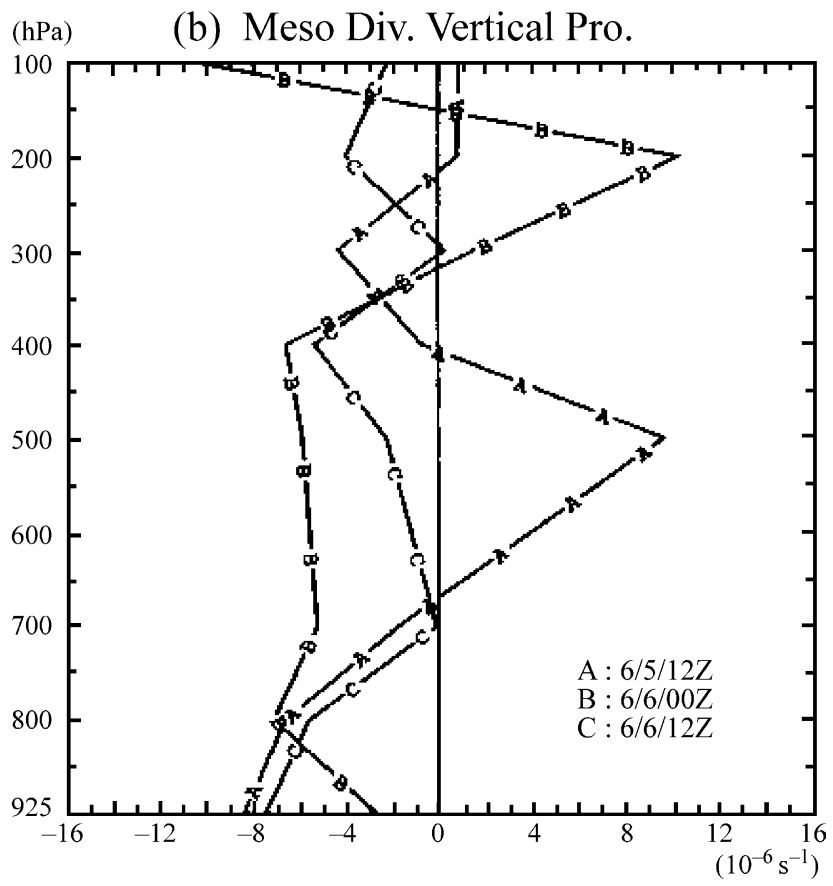

Fig. 13. Vertical profiles of mesoscale a relative vorticity $\left(10^{-6} \mathrm{~s}^{-1}\right)$, b divergence $\left(10^{-6} \mathrm{~s}^{-1}\right)$, and c vertical velocity $\left(\mathrm{hPa} \mathrm{h}^{-1}\right)$ averaged over $5^{\circ} \times 5^{\circ}$ boxes at the locations of the MCS (as shown in Fig. 6a) for 1200 UTC June 5 (curve A), 0000 UTC (curve B) and 1200 UTC (curve C) June 6

about $35-60 \%$ to $60-90 \%$ between 200 and $850 \mathrm{hPa}$ (now shown).

Vertical profiles of horizontal moisture flux convergence and relative humidity averaged inside the $5^{\circ} \times 5^{\circ}$ boxes at 1200 UTC June 5 (curve A) and 0000 UTC June 6 (curve B) are presented in Fig. 15. During the development of the MCS, moisture flux convergence increased at all levels, except at $925 \mathrm{hPa}$ (Fig. 15a). Although the maximum moisture flux convergence in 
(a) $199206 / 0512 \mathrm{Z} 850 \mathrm{hPa}$ Conv-q $\left(10^{-7} \mathrm{~s}^{-1}\right)$

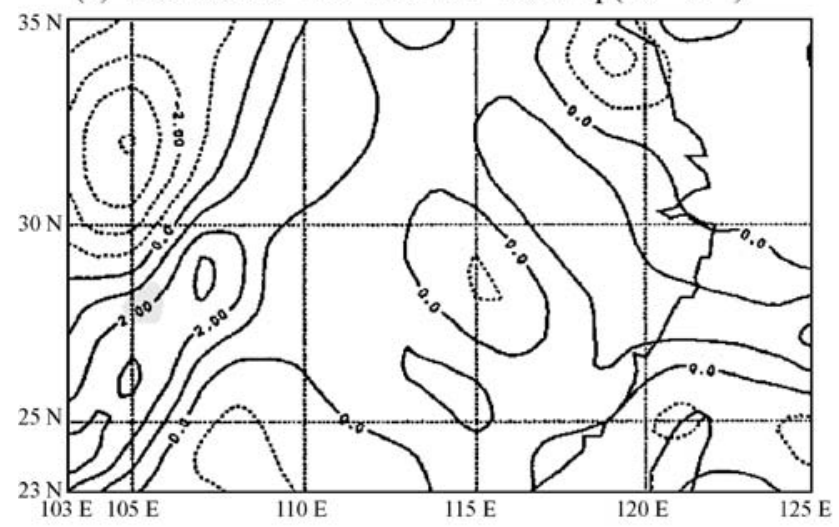

(c) $199206 / 0612 \mathrm{Z} 850 \mathrm{hPa}$ Conv-q $\left(10^{-7} \mathrm{~s}^{-1}\right)$

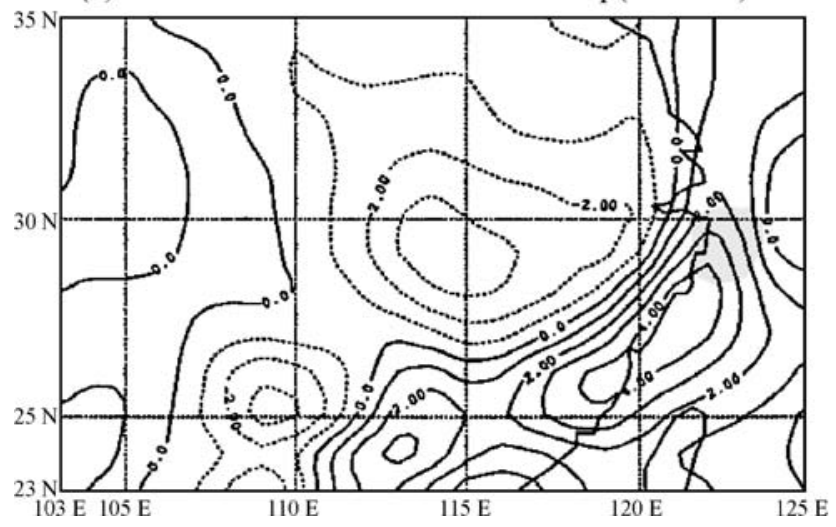

the lower troposphere remained near $2.3 \times 10^{-4} \mathrm{~g} \mathrm{~kg}^{-1} \mathrm{~s}^{-1}$, the top of the layer with positive values ascended from about $600 \mathrm{hPa}$ to $200 \mathrm{hPa}$, in agreement with the evolution in mesoscale divergence and vertical velocity (Fig. 13b,c). The relative humidity profiles indicate that initially $700 \mathrm{hPa}$ had the highest relative humidity (about 68\%), while $300 \mathrm{hPa}$ was the driest (30\%, Fig. 15b). The enhanced moisture convergence in the troposphere led to an increase in relative humidity at all levels, by about $20-35 \%$ before 0000 UTC June 6, as described earlier. Thus, the averaged relative humidity within the $5^{\circ} \times 5^{\circ}$ boxes reached at least $65 \%$ at all levels, and was as high as $82-87 \%$ below $700 \mathrm{hPa}$ in the mature stage of the MCS.

Figure $16 \mathrm{a}, \mathrm{b}$ presents the vertical profiles of apparent heat source $\left(Q_{1}\right)$ and apparent moisture sink $\left(Q_{2}\right)$ averaged over the rectangular boxes for areas of convective cloud (curve A), and northern (B) and western (C) stratiform clouds (Fig. 6b) for the 12-h period between 1200 UTC June 5 and 0000 UTC June 6 . These curves were computed as the sum of local change and 3-D con- (b) $199206 / 0600 \mathrm{Z} 850 \mathrm{hPa}$ Conv-q $\left(10^{-7} \mathrm{~s}^{-1}\right)$

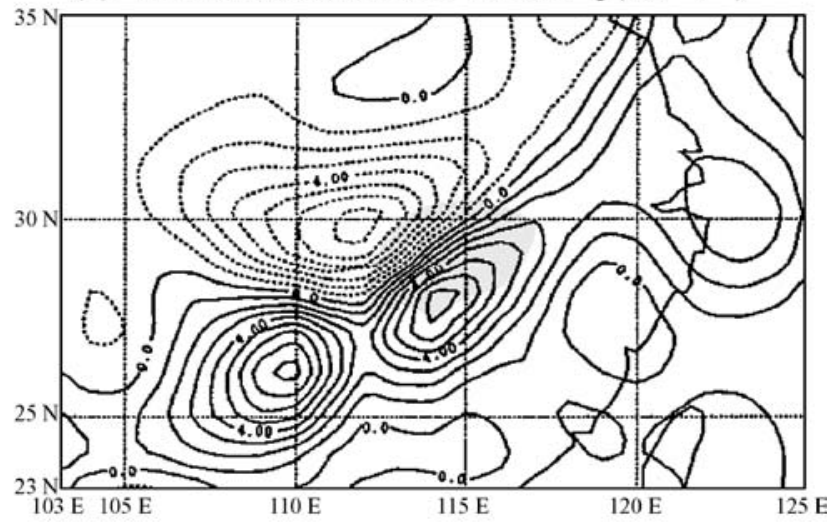

Fig. 14. $850-\mathrm{hPa}$ horizontal moisture flux convergence $\left(10^{-4} \mathrm{~g} \mathrm{~kg}^{-1} \mathrm{~s}^{-1}\right)$ at a 1200 UTC June 5, and b 0000 UTC June 6, and c 1200 UTC June 6. Contour intervals are $1 \times 10^{-4} \mathrm{~g} \mathrm{~kg}^{-1} \mathrm{~s}^{-1}$, with solid lines (positive) indicating moisture convergence and dashed lines (negative) indicating moisture divergence. Shadings indicate regions of the MCS with cloud-top temperature below $-52^{\circ} \mathrm{C}$

vergence/divergence of fluxes based on Eqs. (2) and (3), using the methods described in Sect. 3.2. It is important to note that due to the coarse resolution of the data, particularly in temporal resolution, some errors must exist in the calculated results. With this in mind, we therefore choose only to discuss the more general and significant features in vertical profiles, and leave the smaller ones untouched.

As the MCS intensified, the convective cloud area exhibited positive $Q_{1}$ values, obviously related to latent heat release, with a maximum heating rate of about $15^{\circ} \mathrm{C}$ day $^{-1}$ at $400-$ $500 \mathrm{hPa}$ (curve A, Fig. 16a). The western stratiform-cloud area was dominated by evaporative cooling below $600 \mathrm{hPa}$ (curve C), reaching $-11^{\circ} \mathrm{C}$ day $^{-1}$ at $850 \mathrm{hPa}$, also consistent with the surface mesohigh (c.f., Fig. 4). Above $600 \mathrm{hPa}$, there were small positive values in $Q_{1}$ (about $5^{\circ} \mathrm{C}_{\text {day }}{ }^{-1}$ at $300-500 \mathrm{hPa}$ ), likely from earlier latent heating since the western stratiform-cloud area was along the track of the MCS (c.f., Fig. 1). The northern stratiform-cloud area had cooling below $450 \mathrm{hPa}$ also likely from 

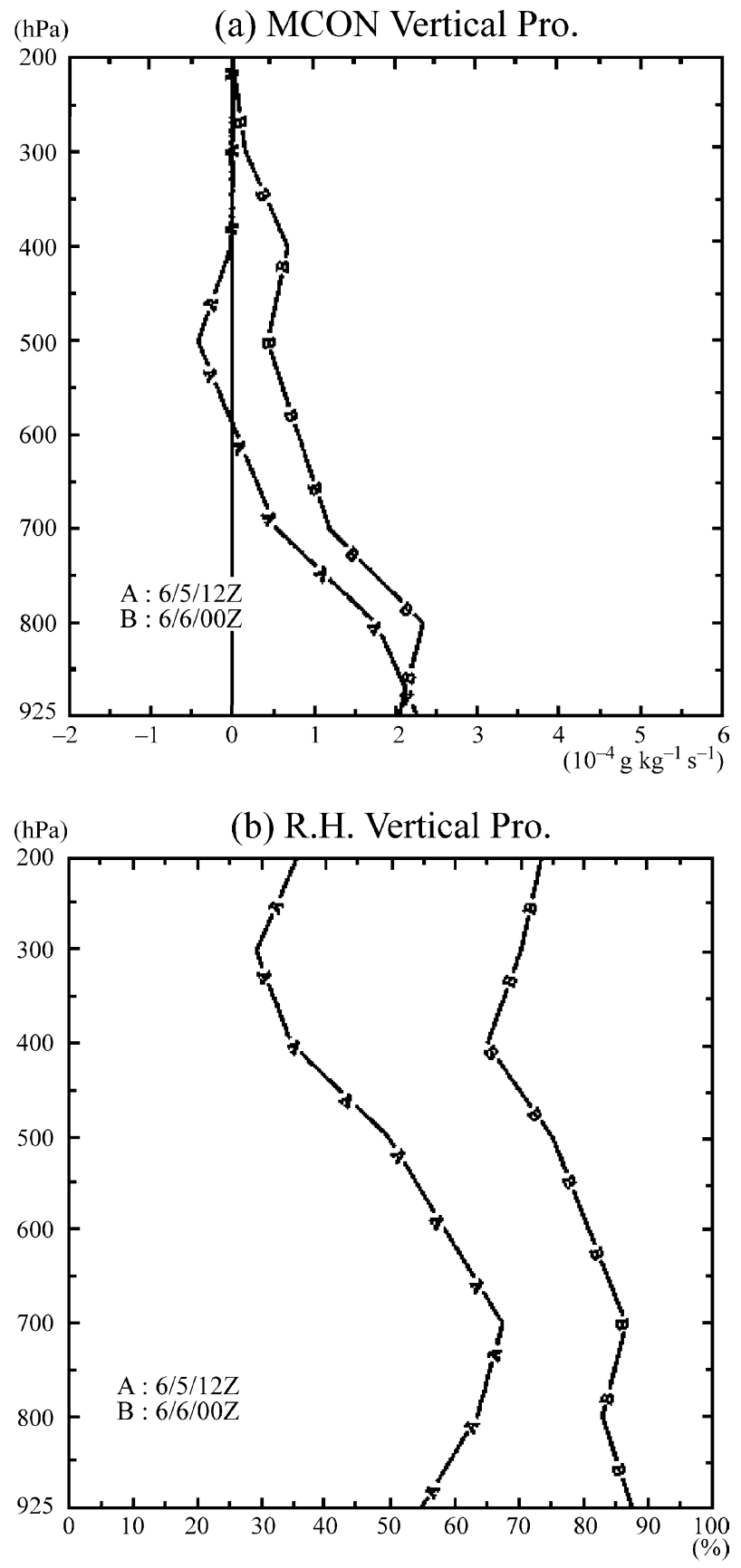

Fig. 15. Vertical profiles of mesoscale a horizontal moisture flux convergence $\left(10^{-4} \mathrm{~g} \mathrm{~kg}^{-1} \mathrm{~s}^{-1}\right)$, and $\mathbf{b}$ relative humidity $(\%)$ averaged over $5^{\circ} \times 5^{\circ}$ boxes at the locations of the MCS (as shown in Fig. 6a) for 1200 UTC June 5 (curve A) and 0000 UTC June 6 (curve B)

evaporation in the subsidence, but the values were quite small (curve B, Fig. 16a).

Vertical profiles of $Q_{2}$ suggest that a small apparent moisture source (negative $Q_{2}$ ) and large sink (positive $Q_{2}$ ) existed over the convective cloud area below and above $700 \mathrm{hPa}$, respectively (curve A, Fig. 16b). For the moisture sink, the net condensational heating reached a maximum of nearly $20^{\circ} \mathrm{C}_{\text {day }}{ }^{-1}$ at $500 \mathrm{hPa}$. The overall shape of positive $Q_{2}$ area, however, was slightly lower than that of $Q_{1}$, and this implies that the vertical transport of sensible heat also played a role in raising $Q_{1}$ above the level of maximum latent heat release. Again consistent with the mesohigh, very strong moisture source existed near the surface of the western stratiform-cloud area, with net evaporative cooling reaching $-40{ }^{\circ} \mathrm{C}_{\text {day }}{ }^{-1}$ at $925 \mathrm{hPa}$ (curve $\mathrm{C}$ ). The features were less significant over the northern stratiform-cloud area, but some evaporative cooling (and negative $Q_{2}$ ) could be seen in the middle troposphere around $500 \mathrm{hPa}$, under the stratiform cloud (curve B).

To further diagnose the source of heating and cooling in the convective cloud, vertical profiles of $Q_{1}$ and $Q_{2}$ budgets with their components, averaged over the $5^{\circ} \times 5^{\circ}$ box at the locations of the MCS (Fig. 6a), are illustrated in Fig. 16c, d, respectively. Since the areas used for averaging were slightly larger, total $Q_{1}$ and $Q_{2}$ curves were not identical from those in Fig. $16 \mathrm{a}, \mathrm{b}$. Profiles of $Q_{1}$ budget from developing to mature stages indicate that the positive $Q_{1}$ due to latent heating reached about $10^{\circ} \mathrm{C}$ day $^{-1}$ at 400 and $500 \mathrm{hPa}$ (curve D). In middle to upper troposphere, the heating led to strong vertical divergence of static energy fluxes with upward vertical velocity, while the horizontal flux produced convergence and negative $Q_{1}$ (curves B and $\mathrm{C}$ ). The difference among curves $\mathrm{B}, \mathrm{C}$, and $\mathrm{D}$ is the local tendency term (curve A), which remained small above $550 \mathrm{hPa}$. Below about $800 \mathrm{hPa}$, on the other hand, 3-D divergence of energy fluxes was positive but total $Q_{1}$ values remained small to slightly negative, hence the former was offset by strong local cooling most likely from evaporation (Fig. 16c). The budget of $Q_{2}$ shows that 3-D convergence of moisture fluxes was associated with condensation above about $800 \mathrm{hPa}$, and produced positive $Q_{2}$ (moisture sink) above $700 \mathrm{hPa}$ (curves $\mathrm{B}$ and $\mathrm{C}$, Fig. 16d). The total $Q_{2}$, however, was significant only above about $600 \mathrm{hPa}$ (curve D), and therefore was strongly counteracted by a local cooling in the lower troposphere centered at $700 \mathrm{hPa}$ (curve A). Thus, the evaporation of precipitation acted as a source of moisture (negative $Q_{2}$ ) and produced cooling of the environment in the lower troposphere at the location of the MCS. 

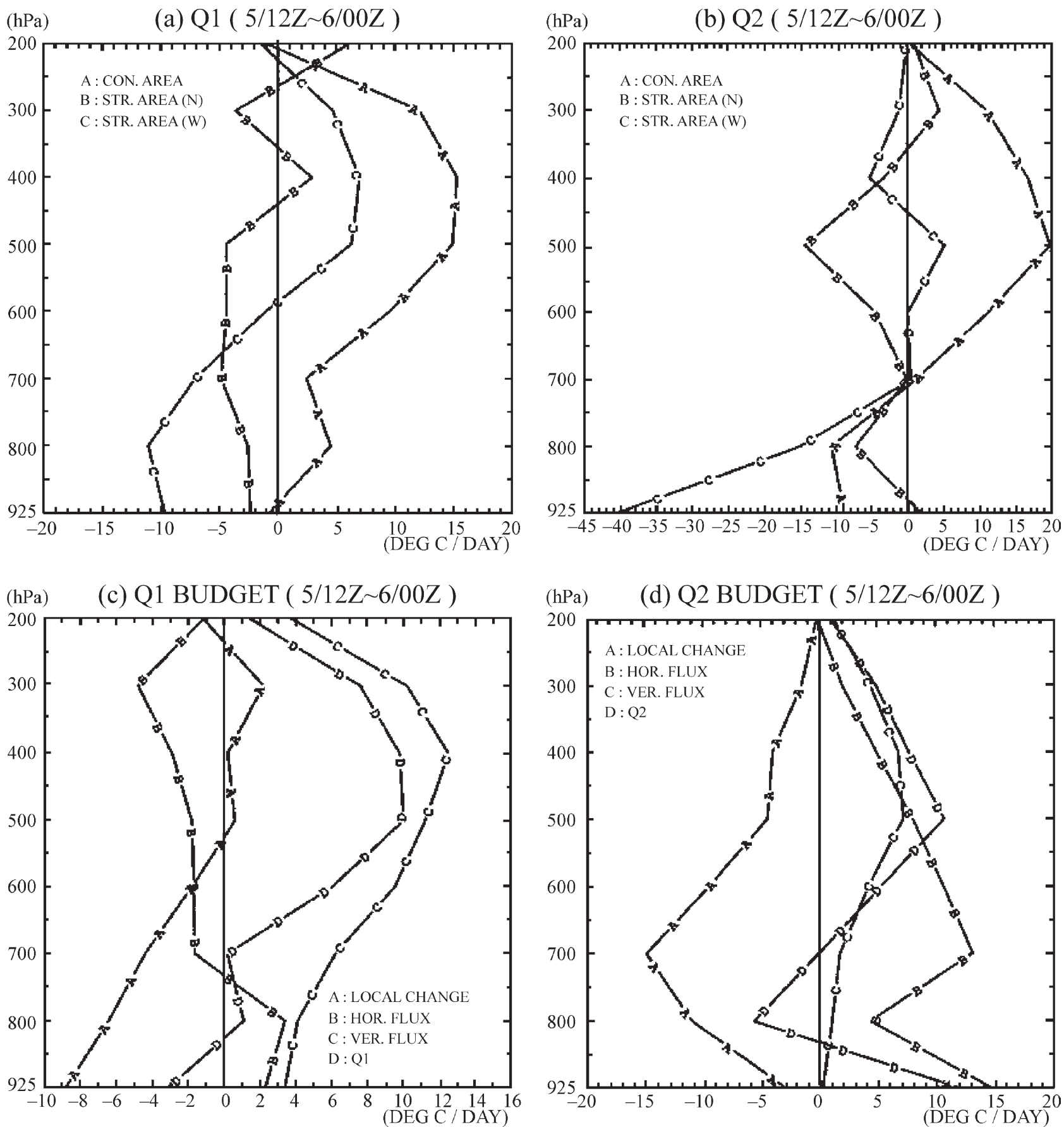

Fig. 16. Vertical profiles of a apparent heat source $\left(Q_{1}\right)$, and $\mathbf{b}$ apparent moisture sink $\left(Q_{2}\right)$ averaged over rectangular boxes (as shown in Fig. 6b) for convective cloud (A), and northern (B) and western (C) stratiform cloud areas during the 12-h period from 1200 UTC June 5 to 0000 UTC June 6. Profiles of contributing terms (local change, and convergence/divergence of horizontal and vertical fluxes) for $Q_{1}$ and $Q_{2}$ averaged over the $5^{\circ} \times 5^{\circ}$ boxes at the locations of the MCS (as shown in Fig. 6a) are shown in $\mathbf{c}$ and $\mathbf{d}$, respectively

\section{Discussion}

Through the use of a scale separation technique (Sect. 3.1), the analysis in Sect. 4 clearly showed that the present MCS case, occurring in southern China, possessed a warm core structure in the middle and upper troposphere due to intense latent heat release as it matured, most evidently at 0000 UTC June 6, 1992 (Fig. 8). The heating produced a mesoscale high-pressure anomaly at $200 \mathrm{hPa}$, and led to the formation of 
an anticyclonic circulation through Coriolis acceleration of ageostrophic winds (Fig. 7). These features are all consistent with those found in MCS cases in North America by Maddox (1980a, b; 1983), Maddox et al (1981), Wetzel et al (1983), and Zhang and Fritsch (1988). The present MCS case was also found to have evident influence on its environment during its mature stage. The warm-core feature in the $300-\mathrm{hPa}$ total temperature field together with the ridge feature associated with the mesohigh at $200 \mathrm{hPa}$ over the area of the MCS suggested the response to latent heating. Moreover, the anticyclonic flow induced by the mesohigh was strongest in its northern ( $>30 \mathrm{kts})$ and western ( $>25 \mathrm{kts})$ branches, and led to a clear diffluent flow pattern near the MCS in the 200-hPa wind field at 0000 UTC June 6 (Figs. 3b and 7h), accompanied by cirrus outflow on satellite imageries (Fig. 2). In addition, the upper-level divergence and anticyclonic vorticity were also present in $200-\mathrm{hPa}$ macroscale fields, which are indications of the influence of the MCS on its environmental atmosphere (Figs. $10 \mathrm{~h}$ and $11 \mathrm{~h})$.

Maddox (1983), and Zhang and Fritsch (1988) also found cooling in the upper troposphere possibly due to radiative cooling and divergent outflow in the mature stage of North American MCSs. In this southern China case, some cooling was observed above $400 \mathrm{hPa}$ at the dissipating stage (Fig. 9b). As for the near-surface features, a mesoscale high and a wake low were both observed under the stratiform-cloud area west of the most intense convection as the MCS matured at 0000 UTC June 6 (Fig. 4). The mesohigh was associated with a cold pool, with strong outflow boundary and a gust front, while the wake low was warm and dry. The low-level divergence, anticyclonic vorticity, and sinking motion northwest of the deep convection (Figs. $10 \mathrm{~b}, 11 \mathrm{~b}$, and $12 \mathrm{~b}$ ), as well as vertical profiles of $Q_{1}$ and $Q_{2}$ over the western stratiform-cloud area (Fig. 16a, b) all indicated that evaporative cooling in downdrafts were responsible for the formation of the mesohigh, in agreement with Zhang and Fritsch (1988). The lack of significant precipitation near the trailing mesolow in the present case (Fig. 4) also agrees with the mechanism offered by Johnson et al (1989) that wake lows form as a result of greater adiabatic warming effect over evaporative cooling when downdrafts are initially drier and contain less liquid water.

The analyses of mesoscale divergence, relative vorticity, and vertical motion in section 4.2 have revealed a series of events that led to the maturity and subsequent dissipation of this particular MCS from its initial development. In the developing stage, the release of latent heat was first confined in the lower and middle troposphere, since the divergence and upward motion were maximized at 500 and $700 \mathrm{hPa}$, respectively (Fig. 13b, c). As the mesohigh developed above the warming layer inside the MCS and vertical motion also transported sensible heat upward (as suggested in Fig. 16c), the level of strongest divergence slowly ascended, and appeared at $200 \mathrm{hPa}$ when the MCS matured (Fig. 13b). During this process, the divergence aloft and lowlevel convergence reinforced one another, and led to strongest upward motion and a deep layer of convergence from the surface up to $350 \mathrm{hPa}$ at 0000 UTC June 6 (Fig. 13b, c). In other words, there existed a positive feedback mechanism for the self-maintenance of the MCS, in which the increased low-level convergence provided more moisture for latent heat release, and the heating led to stronger upper-level divergence that in turn enhanced the convergence at low levels. Such a feedback must have existed in this MCS case, since there was little forcing of larger scale $(>1000 \mathrm{~km})$ that could enhance the upward motion (Fig. 7d). This argument is also supported by the increase in both the convergence of horizontal moisture flux and in relative humidity from 1200 UTC June 5 to 0000 UTC June 6 (Fig. 15). The feedback mechanism appears to be similar to the one existing in the conditional instability of the second kind (CISK), and can potentially be a significant difference between MCS development in the subtropical Asia and in the North America. Further research is needed to clarify this possibility and to shed some light on a more complete understanding of MCSs worldwide. For the upward propagation of the level of strongest ascent, nevertheless, it was also observed in North American MCSs and discussed by Maddox (1983). Eventually, the divergence rose into the level with strong westerlies and became decoupled with the low-level convergence, and the MCS weakened. In our present case, at dissipating stage the strongest divergence 
at 200-hPa moved to the southwest of the MCS, to a region of active new cell development (Fig. 10g).

Mid-level cyclonic vortices, or MCVs, often form in MCS cases over the North America during mature and dissipating stages (e.g., Leary and Rappaport, 1987; Johnson et al, 1989; Zhang et al, 1989; Menard and Fritsch, 1989; Bartel and Maddox, 1991; Johnson and Bartel, 1992; Fritsch et al, 1994), and have largest cyclonic vorticity near $700 \mathrm{hPa}$. It was also suggested that a MCV was generated by the MCS in a case study of a heavy rain event in southern China by Ma and Bosart (1987). In the present case in southern China, however, little indication existed for the presence of such a vortex (Fig. 13a).

Lin (1988), and Chen and Li (1995) have suggested that upper-level diffluence is a favorable condition for MCS development over southern China and Taiwan. Our present case indicates, on the other hand, that upper-level diffluence and divergent outflow can just well be the product of the MCS in its environment. As the mesohigh and divergence reaches the jet stream level, and becomes decoupled with the low-level moisture supply in the development sequence discussed earlier, the MCS will start to dissipate gradually. Therefore, evident cirrus outflow in satellite imageries and strong environmental westerlies are often observed to be the precursor of the weakening of well-developed MCSs. The present MCS case over southern China developed without a nearby Mei-Yu front, and mesoscale processes were of primary importance with relatively little forcing from the larger scale, as shown in Sect. 4. Indeed, only under similarly weak synoptic conditions can a MCS exert and show clearly visible influences on its atmospheric environment.

\section{Conclusions}

The present study diagnosed a MCS case developed under relatively weak synoptic forcing on June 5-6 over southern China during the PostTAMEX forecast experiment in 1992. As this system matured at 0000 UTC June 6 , it was accompanied by clear diffluent flow pattern in the upper troposphere and evident cirrus outflow on satellite imageries.
Twelve-hourly data from 1200 UTC June 5 to 1200 UTC June 6 were used to examine possible effects of this MCS case on its environment. Objective analyses were performed to retrieve data on a $1^{\circ} \times 1^{\circ}$ latitude/longitude grid by using a low-pass filter (Barnes 1964; 1973). To facilitate the diagnosis, further scale separation technique using a band-pass filter (Doswell, 1977) was utilized to distinguish mesoscale and macroscale features. The apparent heat source $\left(Q_{1}\right)$ and apparent moisture sink $\left(Q_{2}\right)$ of Yanai et al (1973) were also calculated and discussed. The results obtained from this southern China case suggest that it had clear influence on its environment, and some aspects were compared with those found in MCSs over North America. Major findings can be summarized as the following:

(1) Latent heat release from the convection of the MCS led to development of a warm core in the middle and upper troposphere and mesoscale high-pressure disturbance at $200 \mathrm{hPa}$. The mesohigh induced ageostrophic flow through geostrophic adjustment, and resulted in diffluent pattern in the large-scale wind field and the cirrus outflow observed in satellite pictures. The $200-\mathrm{hPa}$ anticyclonic circulation associated with the MCS was strongest in the northern and western branches, and caused the environmental westerlies to be stronger to the north and weaker to the south of the mesohigh. At upper levels, strong divergence and anticyclonic vorticity were also reflected in the large-scale fields.

(2) The divergence induced by the mesohigh was initially maximized at $500 \mathrm{hPa}$ in the developing stage of the MCS, then rose to $200 \mathrm{hPa}$ in the mature stage. In response, the altitude at which maximum vertical velocity occurred also increased from 700 to about $350 \mathrm{hPa}$ in the mature stage and intensified. A positive feedback mechanism is believed to exist between the low-level moisture convergence and upper-level divergence, so the MCS was self-maintained during its intensification. The upward transport of sensible heat by the updrafts inside the MCS was important in causing the ascent of the divergent levels.

(3) Weak cooling occurred in the upper troposphere after the mature stage in the present 
MCS case, likely due to radiative cooling. A mid-level cyclonic vortex (MCV) that often presents in MCS cases over the North America, however, was not apparent in the case here mainly because the magnitudes of environmental vorticity and $f$ were insufficient for the vortex stretching process to be effective.

(4) Near the surface, both a cold mesohigh and a warm trailing low formed over the region of subsidence under the stratiform clouds, to the west of the deep convection. The cold pool was associated with strong outflow boundary and a gust front. Analysis of $Q_{1}$ and $Q_{2}$ indicates that the mesohigh formed due to evaporation in the downdrafts, while the wake low likely formed through near-adiabatic warming of drier descending air that contained less liquid water.

\section{Acknowledgement}

Constructive comments from two anonymous reviewers are greatly appreciated, and helped to improve the quality of the manuscript. The authors also wish to thank Mr. C.-C. Lin and I.-M. Tang for processing the figures. This study was supported by the National Science Council of Taiwan, ROC under Grant No. NSC-90-2119-M-002-010 and NSC90-2119-M-002-011.

\section{References}

Bartels DL, Maddox RA (1991) Midlevel cyclonic vortices generated by mesoscale convective systems. Mon Wea Rev 119: 104-117

Barnes SL (1964) A technique for maximizing details in numerical weather map analysis. J Appl Meteor 3: 396-409

Barnes SL (1973) Mesoscale objective map analysis using weighted time series observations. NOAA Tech Memo, ERL NSSL-62, 60 pp

Chen GTJ, Wu CW, Chi SS (1986) Climatological aspects of the mesoscale convective systems over subtropical China and the western North Pacific during Mei-Yu season of 1981-83. Atmos Sci 13: 33-45 (in Chinese with English abstracts)

Chen YL, Li J (1995) Large-scale conditions favorable for the development of heavy rainfall during TAMEX IOP 3. Mon Wea Rev 123: 2978-3002

Chi SS, Chen GTJ (1988) A diagnostic case study of the environmental conditions associated with mesoscale convective complexes: 27-28 May 1981 case. Atmos Sci 16: 14-30 (in Chinese with English abstracts)

Cox SK, Griffith KT (1979) Estimates of radiative divergence during phase III of the GARP Atlantic Tropical Experiment: Part II. Analysis of phase III results. J Atmos Sci 36: 586-601
Doswell CA (1977) Obtaining meteorologically significant surface divergence fields through the filtering property of objective analysis. Mon Wea Rev 105: 885-892

Doswell CA, Ramis C, Romero R, Alonso S (1998) A diagnostic study of three precipitation episodes in the western Mediterranean region. Wea Forecast 13: 102-124

Fritsch JM, Murphy JD, Kain JK (1994) Mesoscale warmcore vortex amplification over land. J Atmos Sci 51: 1780-1807

Fujita TT (1959) Precipitation and cold air production in mesoscale thunderstorm systems. J Meteor 16: 454-466

Holton JR (1992) An introduction to dynamic meteorology. 3rd ed. San Diego, CA: Academic Press, 511 pp

Johnson RH, Chen S, Toth JJ (1989) Circulations associated with a mature-to-decaying midlatitude mesoscale convective system. Part I: Surface features-heat bursts and mesolow development. Mon Wea Rev 117: 942-959

Johnson RH, Bartels DL (1992) Circulation associated with a mature-to-decaying midlatitude mesoscale convective system. Part II: Upper level features. Mon Wea Rev 120: 1301-1320

Laing AG, Fritsch JM (1997) The global population of mesoscale convective complexes. Quart J Roy Meteor Soc 123: 389-405

Laing AG, Fritsch JM (2000) The large-scale environments of the global population of mesoscale convective complexes. Mon Wea Rev 128: 2756-2776

Leary CA, Rappaport EN (1987) The life cycle and internal structure of a mesoscale convective complex. Mon Wea Rev 115: 1503-1527

Lin SC, Chiou TK (1985) Objective scale separation technique and its application on the mesoscale convective system diagnosis. Papers Meteor Res 78: 69-94

Lin SC (1988) The life cycle and structure of a mesoscale convective system occurring in the southern China area during Mei-Yu season. Papers Meteor Res 81: $1-26$

Loehrer SM, Johnson RH (1995) Surface process and precipitation life cycle characteristics of PRE-STORM mesoscale convective systems. Mon Wea Rev 123: 600-621

Ma KY, Bosart LF (1987) A synoptic overview of a heavy rain event in southern China. Wea Forecast 2: 89-112

Maddox RA (1980a) Mesoscale convective complexes. Bull Amer Meteor Soc 61: 1374-1387

Maddox RA (1980b) An objective technique for separating macro-scale and mesoscale features in meteorological data. Mon Wea Rev 108: 1108-1121

Maddox RA, Perkey DJ, Fritsch JM (1981) Evolution of upper tropospheric features during the development of a mesoscale convective complex. J Atmos Sci 38: 1664-1674

Maddox RA (1983) Large-scale meteorological conditions associated with midlatitude mesoscale convective complex. Mon Wea Rev 111: 1475-1493

Menard RD, Fritsch JM (1989) A Mesoscale convective complex-generated inertially stable warm core vortex. Mon Wea Rev 117: 1237-1261

O'Brien JJ (1970) Alternative solution to the classical vertical velocity problem. J Appl Meteor 9: 197-203 
Trier SB, Davis CA, Tuttle JD (2000) Long-lived mesoconvective vortices and their environment. Part I: Observations from the central United States during 1998 warm season. Mon Wea Rev 128: 3376-3395

Wetzel PJ, Cotton WR, McAnelly RL (1983) A long-lived mesoscale convective complex. Part II: Evolution and structure of the mature complex. Mon Wea Rev 111: 1919-1937

Yanai M, Esbensen S, Chu JH (1973) Determination of bulk properties of tropical cloud clusters from largescale heat and moisture budgets. J Atmos Sci 30: 611-627

Zhang DL, Fritsch JM (1988) A numerical investigation of a convective generated, inertially stable, extratropical warm-core mesovortex over land. Part I: Structure and evolution. Mon Wea Rev 116: 2660-2687
Zhang DL, Gao K, Parsons DB (1989) Numerical simulation of an intense squall line during 10-11 June 1985 prestorm. Part I: Model verification. Mon Wea Rev 117: 960-994

Zipser EJ (1977) Mesoscale and convective-scale downdrafts as distinct components of squall-line circulation. Mon Wea Rev 105: 1568-1589

Authors' addresses: George Tai-Jen Chen, Department of Atmospheric Sciences, National Taiwan University, Taipei, Taiwan 10772, ROC (E-mail: george@george2.as.ntu. edu.tw); Chung-Chieh Wang, Department of Environmental Management, Jin-Wen Institute of Technology, Hsin-tien, Taipei, Taiwan 231, ROC (E-mail: cwang716@ms41.hinet. net); Chang-Sheng Hsieh, South Regional Meteorological Center, Central Weather Bureau, Tainan, Taiwan, ROC 